\title{
Rapid Extraction of Quantitative Kinetic Information from Variable-Temperature Reaction Profiles
}

Daniel H. Coller, ${ }^{\mathrm{a}}$ Brian C. Vicente, ${ }^{\mathrm{a}}$ Susannah L. Scott ${ }^{\mathrm{a}, \mathrm{b}, *}$

${ }^{a}$ Department of Chemical Engineering, and ${ }^{b}$ Department of Chemistry and Biochemistry, University of California, Santa Barbara, California 93106, United States

*Corresponding author. Tel. 1805893 5606; Fax: 18058934731.

E-mail: sscott@engineering.ucsb.edu (S.L.S.)

Keywords: reaction profiles, variable-temperature kinetics, global curve-fitting, activation parameters 


\section{ABSTRACT}

Analysis of variable-temperature reaction profiles, measured in an isothermal packed-bed reactor (PBR) whose temperature increases during the experiment, has the potential to yield accurate and precise kinetic parameters quickly for some heterogeneous catalysts. The method is demonstrated here for a typical supported nanoparticle catalyst, $2 \mathrm{wt} \% \mathrm{Pd} / \mathrm{Al}_{2} \mathrm{O}_{3}$, in the oxidation of $\mathrm{H}_{2}, \mathrm{C}_{3} \mathrm{H}_{8}$ and $\mathrm{CO}$ by $\mathrm{O}_{2}$. These reactions do not exhibit major changes in activation energy as a function of conversion over the range of reaction conditions analyzed. Reliable and quantitative information about rate laws was extracted readily from the shapes and positions of these profiles, as an alternative to more laborious conventional kinetic analyses. Temperature and pressure gradients were minimized by the use of sieved catalyst particles and large amounts of inert diluent for both the catalyst and feed gas. Curve-fitting of analytical expressions with as few as two adjustable parameters results in remarkable agreement between models and data. First-order profiles are indeed kinetically-limited, without mass and heat transfer effects, while inverse-firstorder profiles deviate from kinetically-controlled behavior at intermediate-to-high conversions. The activation energy and reaction order with respect to the limiting reactant obtained from a single reaction profile (with appropriate data truncation for non-kinetic phenomena, as necessary) are at least as accurate and precise as those obtained from a conventional Arrhenius analysis conducted with data obtained under differential conditions, and are measured in a fraction of the experimental time. Information about more elaborate rate laws can be obtained by global curve-fitting of a family of such profiles recorded with different volumetric flow rates. 


\section{Introduction}

\subsection{Expanding the scope of traditional kinetic analysis in flow reactors}

As high-throughput methods for materials synthesis become more versatile and accessible [1], large numbers of heterogeneous catalysts covering a wide range of composition space can be generated quickly [2-4], creating a need for similarly fast and flexible methods to screen for catalytic activity. Comparing performance in a catalyst array at a common temperature has limited usefulness, because the onset of activity can be abrupt for surface-mediated reactions. Comparing temperatures for $50 \%$ conversion of a limiting reactant, $T_{50}$, can also be problematic, because this single-point measurement may be strongly influenced by non-kinetic effects. Even when this is not the case, such comparisons are valid only for measurements made under the same conditions (residence time, feed composition, dispersion of the active phase, etc.), and for catalysts that follow the same rate law. A more robust kinetic assessment requires measurement of reaction orders and activation parameters over a range of operating conditions, which is typically slow and labor-intensive even for a single catalyst. Even more time-consuming is the assembly of a microkinetic model, requiring extensive measurements across a wide range of experimental conditions to identify and quantify the rates of all elementary steps. Nevertheless, acquiring as much of this information as possible for a series of heterogeneous catalysts in a variety of reaction atmospheres is ultimately necessary for properly interpreting reactivity differences, rationalizing the search for and design of new catalysts, benchmarking and optimizing their performance [5].

While some kinetic descriptors, such as the turnover frequency (TOF), can be obtained relatively quickly [6], direct comparisons are still difficult, especially when a series of catalysts exhibits widely varying activities. A recent proposal [7] to create a "standard" TOF suffers from 
the need to make long extrapolations, and TOFs can be mis-used in such comparisons [8]. The empirical Arrhenius parameters $A$ (or $k_{0}$ ) and $E_{\mathrm{a}}$ are more generally useful. Ideally, they should be obtained from the temperature dependence of a rate constant, which in turn implies

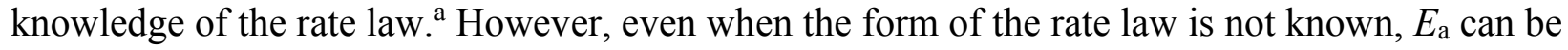
extracted from the temperature dependence of the conversion $(X)$ at the outlet of a packed bed reactor (PBR) operated under differential conditions. Obviously, the same information is available from the temperature dependence of the reaction rate $\left(-r_{\mathbf{a}}\right)$, computed from the product of $X$ and $F_{\mathbf{a}, 0}$ (the molar flow rate of the limiting reactant a, which is proportional to both the inlet concentration of a and the volumetric flow rate) and normalized by the catalyst weight $W$, as in Eq. 1. The ratio $W / v_{0}$ is the PBR version of the space-time, $\tau$.

$-r_{\mathbf{a}}=\frac{F_{\mathrm{a}, 0} X}{W}=\frac{C_{\mathrm{a}, 0} v_{0} X}{W}=\frac{C_{\mathrm{a}, 0} X}{\tau}$

In a conventional PBR kinetic analysis, the reaction orders are assessed in a series of isothermal, steady-state experiments for which the inlet concentration of each chemical component is varied independently while keeping the conversion very low. The activation parameters are extracted from the response of the outlet conversion to changes in temperature. The need for differential reaction conditions to ensure kinetic control of the rate imposes important constraints on kinetic experiments: (1) The measurements themselves, made at very low conversions, are often inherently imprecise. (2) Keeping the temperature range small to maintain low conversion contributes to a large (and often unacknowledged) uncertainty in the

\footnotetext{
${ }^{a}$ If $k$ is a rate constant for an elementary step, an Eyring plot $\left([\ln (k / T)]\right.$ vs. $\left.T^{-1}\right)$, is preferred because it gives the physically meaningful activation parameters $\Delta H^{\ddagger}$ and $\Delta S^{\ddagger}$. However, most measurements in heterogeneous catalysis generate apparent rate constants that contain multiple unresolved contributions from adsorption/desorption and reaction steps. In such cases, the empirical Arrhenius treatment is usually considered satisfactory.
} 
Eyring and/or Arrhenius parameters. (3) Perhaps most significantly, experiments performed at low conversion over a limited temperature range inevitably exclude the majority of reaction conditions, including those which are likely to be most relevant to practical reactor operation.

Even for a single catalyst, a complete kinetic study requires many experiments over an extended period of time, for which maintaining stable operation of the catalyst and reactor can be challenging. For catalysts that deactivate relatively rapidly [9], the need to conduct lengthy steady-state kinetics experiments is particularly problematic, and would benefit from a faster, variable-temperature approach. For example, the kinetic analysis of $\mathrm{CO}$ oxidation by a new, single-site Pd catalyst was limited to a single data point at each reactor condition, and steadystate operation was never achieved, due to rapid catalyst deactivation [10]. Finally, the linearization used in conventional methods of analysis for differential kinetic data alters the weighting of experimental values, and yields parameters that are susceptible to correlations [1113]. Consequently, distinguishing between kinetic models can be prone to error, and complex behavior can be masked. More accurate and discriminating methods using non-linear analysis of variable-temperature kinetic data (collected by increasing the reactor temperature continuously) have long been available $[14,15]$, although they have yet to be widely adopted.

\subsection{Potential benefits of variable-temperature kinetic investigation}

Much of the kinetic information one usually seeks (rate law, activation parameters) is contained in the light-off profile. According to one definition, catalyst "light-off" occurs at the transition between the kinetically-controlled low temperature regime and the diffusion-controlled high temperature regime. However, with appropriate choice of reactor conditions, the entire $X-T$ plot can be recorded under predominantly kinetically-controlled conditions, and is still 
commonly called a light-off profile. Here, we name such data, which is free of transport influences and collected while increasing the reactor temperature at a fixed rate, a reaction profile. Although the full reaction profile constitutes a non-isothermal experiment, the entire catalyst bed remains approximately isothermal for the duration of an individual $X-T$ measurement. A flat-bed reactor has also been used to minimize thermal gradients in the catalyst, so that they can be neglected [16].

Such reaction profiles are rarely used to extract kinetic parameters (other than the activation energy, from the leading edge of the curve) even though their analysis could alleviate several of the drawbacks of differential kinetic work. These include differences in feed and catalyst bed characteristics across a series of isothermal runs, and changes in the catalyst that take place while the reactor is being heated to each desired temperature, giving the material a complex thermal history. A method for the quantitative analysis of reaction profiles could dramatically reduce the amount of time necessary to assess kinetic parameters for large numbers of heterogeneous catalysts, or for a small number of catalysts under a wide range of reaction conditions. In principle, it allows several kinetic parameters to be measured in a single experiment, minimizing the use of time and material and providing rapid results to guide catalyst synthesis based on performance. This in turn would allow researchers to allocate more resources to their most promising leads, and to reduce time spent on catalysts with inadequate properties.

Since reaction profiles cover a large temperature range, they represent much richer kinetic datasets (thereby increasing the accuracy of derived kinetic parameters), and allow the validity of a proposed rate law to be assessed over a wider range of conversions. This in turn results in a more robust and versatile reaction model which more completely describes the behavior of reactors operating at high conversion and in the presence of temperature gradients. 
As a corollary, abrupt or gradual changes in kinetic behavior (signaled by deviation from the expected shape of the reaction profile, or changes in the curve-fit parameters) can be used to identify precisely the conditions where the reaction mechanism and/or the nature of the active sites change, or where the onset of mass transfer-limited behavior occurs.

\subsection{Precedents and challenges in variable-temperature kinetic analysis}

Rate data collected under variable-temperature conditions have long been used to provide quantitative kinetic information in fields other than heterogeneous catalysis. In thermal analysis, they are analyzed to determine activation parameters for solid-state phase transitions and decomposition reactions $[17,18]$. For example, thermo-gravimetric analysis (TGA) records the decrease in mass that reflects the progress of a solid-state reaction $[19,20]$. Temperatureprogrammed desorption (TPD) from surfaces reveals information about adsorbate binding [21] (although parameters can be complicated by readsorption, especially in the case of porous materials [22]). Variable-temperature kinetics (VTK, also sometimes called non-isothermal kinetics) has been used to accelerate pharmacological screening of drug candidates for their thermal, hydrolytic and oxidative stability [23].

VTK approaches have been used to obtain kinetic information about liquid-phase organic reactions, including base-catalyzed hydrolysis [24-26] and esterification [27]. Inorganic reactions studied using VTK methods include isomerization [28, 29] and oxidative addition [30], as well as ligand substitution reactions of metal complexes [31]. In some of these liquid-phase batch studies, similar accuracy for kinetic parameters and model discrimination was reported for both isothermal and variable-temperature methods, although the latter gave results several orders of magnitude faster (since far fewer experiments were required). In other studies, analysis of 
variable-temperature experiments was found to be both faster and more accurate, principally because statistical errors decrease when vastly more kinetic data is collected.

Interpreting VTK for gas-phase reactions in a non-stirred flow reactor is a significantly more challenging task, because the results are often strongly convoluted with non-kinetic effects. Gradients in temperature, pressure and concentration may exist inside the reactor, and inside individual catalyst particles. Feed gases may bypass solid catalyst particles in a packed bed. Nevertheless, there have been attempts to extract kinetic information from transient data recorded in flow reactors during a temperature ramp, particularly in catalytic converter studies, where predictive models are required for vehicle-specific decisions about catalyst configurations. For this application, the low temperature (cold-start) performance is important, and quantitative predictions of engine emissions are required at non-differential conversion. Large transients in temperature, gas composition, and flow rate are typical of real operating conditions.

One approach is to simulate kinetic behavior in a near-adiabatic catalyst monolith or packed-bed reactor using the mass and energy balances for both the gas and solid phases in a 1D plug-flow model. The equations can be solved sequentially until convergence using manually adjusted parameters, or residual minimization methods. Another approach is to simulate reaction profiles using kinetic parameters measured for individual reaction steps by conventional methods. Reactions studied using both methods vary from simple CO oxidation [32-36] to CO oxidation in the presence of $\mathrm{H}_{2}[37,38]$, the $\mathrm{CO}-\mathrm{NO}$ reaction [32,34], hydrocarbon combustion [32, 34, 39], and methanol steam-reforming [39, 40]. In all of these cases, only approximate agreement was observed between the experimental and simulated profiles, both for global models (based on power rate laws), and for microkinetic models. The latter often have large 
numbers of adjustable parameters, and even fixing some of them based on prior knowledge yields optimized parameter sets that are not unique.

The better heat and mass transfer characteristics of the PBR relative to monoliths result in activity profiles that are more representative of intrinsic kinetics. When the temperature ramp rate is slow relative to the reactor residence time, and the heat of reaction is minimized by dilution of the feed gas with an inert, the catalyst bed remains close to isothermal during the measurement time. In one such study, the shape of the reaction profile was used to discriminate between positive and negative reaction orders with respect to the limiting reactant, and to identify the transition from kinetically-limited to mass transfer-limited conditions, using the relation between conversion and reactor temperature [41]. However, while agreement between the curve-fits and experimental data for $\mathrm{CO}$ oxidation and methane combustion was quite good $[41,42]$, the resulting kinetic parameters were not deemed reliable.

A method of temperature scanning in a plug-flow reactor (TS-PFR) was developed to increase the rate of data acquisition by making simultaneous measurements of space-time, reactor exit temperature, and outlet concentrations [15]. Numerical differentiation of the smoothed conversion data with respect to the space-time gave the reaction rate as a function of temperature. However, the fits were difficult to assess visually; instead, models were compared via the magnitudes of the sums of squared errors. For example, $\mathrm{CO}$ oxidation over $\mathrm{Pt} / \gamma-\mathrm{Al}_{2} \mathrm{O}_{3}$ was examined with a view to determine the reaction order with respect to $\mathrm{O}_{2}$ using LangmuirHinshelwood models with eight adjustable parameters. Global analysis for several feed rates was conducted using more than 10000 data points. Results analyzed over the full range of conversion gave smaller uncertainties in the fit parameters for a dissociative adsorption model (i.e., halforder in $\mathrm{O}_{2}$ ), compared to a molecular adsorption model (i.e., first-order in $\mathrm{O}_{2}$ ), although some 
parameters were highly correlated and not unique [43]. Similarly, temperature-scanning data from methanol steam-reforming over a $\mathrm{Cu} / \mathrm{ZnO} / \mathrm{Al}_{2} \mathrm{O}_{3}$ catalyst was analyzed with a 20 -parameter Langmuir-Hinshelwood model, for which 7 parameters were fixed at known values [44]. Modest agreement with the literature for the remaining adsorption and activation enthalpies and entropies suggested that the results were not quantitative.

\subsection{Objectives}

A general method to extract reliable kinetic parameters from integral $X-T$ data for heterogeneously-catalyzed reactions has yet to be reported. Here, we show that analysis of kinetically-controlled variable-temperature reaction profiles can be fast, simple to implement, and easy to assess for agreement between experiment and model. The straightforward analytical method does not depend on the availability of extensive prior kinetic information, and the results are quantitatively comparable to those obtained by conventional kinetic analysis (e.g., differential conversion at steady-state in a continuous flow reactor). Since there is no need for long waiting periods associated with data acquisition under isothermal steady-state conditions, experiments can be conducted much faster, and catalyst deactivation is less problematic. The method is applied to the catalytic oxidation of $\mathrm{CO}, \mathrm{H}_{2}$ and propane, all of which are key reactions in vehicle emissions control during catalyst warmup.

\section{Experimental methods}

\subsection{Materials}


The catalyst selected to explore reaction profile analysis is $2.0 \mathrm{wt} \% \mathrm{PdO}$ supported on $\gamma$ $\mathrm{Al}_{2} \mathrm{O}_{3}$ (Sasol HTA-102, surface area $76 \mathrm{~m}^{2} \mathrm{~g}^{-1}$, pore volume $0.60 \mathrm{~cm}^{3} \mathrm{~g}^{-1}$, median pore radius 15 $\mathrm{nm}$ ), hereafter called $\mathrm{Pd} / \mathrm{Al}_{2} \mathrm{O}_{3}$. It was prepared by incipient wetness impregnation of the $\gamma-\mathrm{Al}_{2} \mathrm{O}_{3}$ with aqueous $\mathrm{Pd}\left(\mathrm{NO}_{3}\right)_{2}$ (Heraeus, $99.99 \%$ ). The resulting solid contains $\mathrm{Pd}$ with an average particle size of $(2.8 \pm 0.6) \mathrm{nm}$ (assessed by transmission electron microscopy). The as-prepared catalyst was dried in air at $100{ }^{\circ} \mathrm{C}$, followed by calcination at $150{ }^{\circ} \mathrm{C}$ for $2 \mathrm{~h}, 450{ }^{\circ} \mathrm{C}$ for $2 \mathrm{~h}$, and $600{ }^{\circ} \mathrm{C}$ for $4 \mathrm{~h}$. To minimize the formation of hot spots in the catalyst bed, the resulting powder (40 mg) was sieved to a mesh size of 80/100 (150-180 $\mu \mathrm{m})$ and diluted with SiC (Sigma Aldrich, $>97.5 \%, 200$ mesh size) in a 1:3 ratio (w/w), unless specified otherwise.

All high purity gasses were supplied by Praxair: Ar (99.999 \%), $\mathrm{O}_{2}$ (99.99 \%, and 5000 ppm in $\mathrm{Ar}, 99.99 \%), \mathrm{CO}_{2}$ (5000 ppm in $\left.\mathrm{Ar}, 99.99 \%\right), \mathrm{CO}$ (5005 ppm in $\left.\mathrm{Ar}, 99.99 \%\right), \mathrm{C}_{3} \mathrm{H}_{8}$ (5138 ppm in Ar, $99.99 \%$ ) and $\mathrm{H}_{2}$ (4913 ppm in $\left.\mathrm{Ar}, 99.99 \%\right)$.

\subsection{Catalytic reaction conditions}

Complete oxidation of $\mathrm{H}_{2}, \mathrm{C}_{3} \mathrm{H}_{8}$, and $\mathrm{CO}$, each catalyzed by $\mathrm{Pd} / \mathrm{Al}_{2} \mathrm{O}_{3}$ in the presence of $\mathrm{O}_{2}$, were chosen as test reactions, in part because their limiting rate laws are simple and no sidereactions are expected. (If side-reactions were present, the shape and position of the profile would be determined by two or more rate laws, which could compromise the ability to describe the shape of the profile accurately using a single rate law.) In addition, their activation parameters vary little with conversion over the range of reaction conditions studied (see below). For $\mathrm{H}_{2}$ oxidation, reaction profiles were recorded under $\mathrm{O}_{2}$-rich conditions relevant to diesel oxidation catalysts $\left(1000 \mathrm{ppm} \mathrm{H}_{2}, 100000 \mathrm{ppm} \mathrm{O}_{2}\right.$, balanced by $\mathrm{Ar}$ ). In this concentration regime, the reaction orders are 0 and 1 with respect to $\mathrm{O}_{2}$ and $\mathrm{H}_{2}$ [45]. Reaction profiles for $\mathrm{C}_{3} \mathrm{H}_{8}$ 
oxidation were also recorded in an $\mathrm{O}_{2}$-rich atmosphere $\left(1000 \mathrm{ppm} \mathrm{C}_{3} \mathrm{H}_{8}, 100000 \mathrm{ppm} \mathrm{O}_{2}\right.$, balanced by Ar). Under these conditions, the reaction orders with respect to $\mathrm{O}_{2}$ and $\mathrm{C}_{3} \mathrm{H}_{8}$ are 0 and $1[46]$.

$\mathrm{CO}$ oxidation was conducted with equimolar reactant concentrations $\left(C_{\mathrm{CO}, 0}=C_{\mathrm{O} 2,0}=\right.$ 1000 ppm, balanced by Ar), relevant to three-way catalysis. Over Pd-based catalysts, CO generally inhibits the reaction rate because its low-temperature adsorption on the metal is much more favorable than that of $\mathrm{O}_{2}$ [47]. In the concentration range studied, the experimentallydetermined reaction orders with respect to $\mathrm{O}_{2}$ and $\mathrm{CO}$ are +1 and -1 [47], resulting in an overall reaction order of zero since the inlet concentrations are similar.

\subsection{Recording reaction profiles}

Variable-temperature kinetic experiments were carried out in a CATLAB micro-reactor (Hiden Analytical). The tubular quartz reactor has an inner diameter of $3.88 \mathrm{~mm}$. The short catalyst bed $(<4 \mathrm{~mm})$ was held in place between two plugs of quartz wool, giving a typical catalyst bed volume of $5 \times 10^{-8} \mathrm{~m}^{3}(0.05 \mathrm{~mL})$. The pressure drop across the bed was measured to be less than 70 mbar. Since the catalyst bed is essentially isothermal during each measurement, the temperature of the entire reactor is described by a single value, measured by a K-type thermocouple (Omega KQXL, $0.05 \mathrm{~s}$ response time) in contact with the front end of the catalyst bed. During variable temperature experiments, the reactor was heated in a tube furnace at a constant rate of $5 \mathrm{~K} \mathrm{~min}^{-1}$. The composition of the effluent gas stream was monitored using a close-coupled online quadrupole mass spectrometer with a response time of $<500 \mathrm{~ms}$ (HR-20, Hiden Analytical). During this time, the change in reactor temperature is less than $0.1 \mathrm{~K}$, which is not considered significant here. A secondary electron multiplier (SEM) detector was used to 
monitor signals for $\mathrm{CO}_{2}(\mathrm{~m} / \mathrm{z}=44), \mathrm{H}_{2}(\mathrm{~m} / \mathrm{z}=2)$, or $\mathrm{C}_{3} \mathrm{H}_{8}$ (via its ethyl fragment, at $\left.\mathrm{m} / \mathrm{z}=29\right)$, whose intensities were recorded every $0.6 \mathrm{~s}$. The reactor setup and experimental design are shown schematically in Fig. 1.

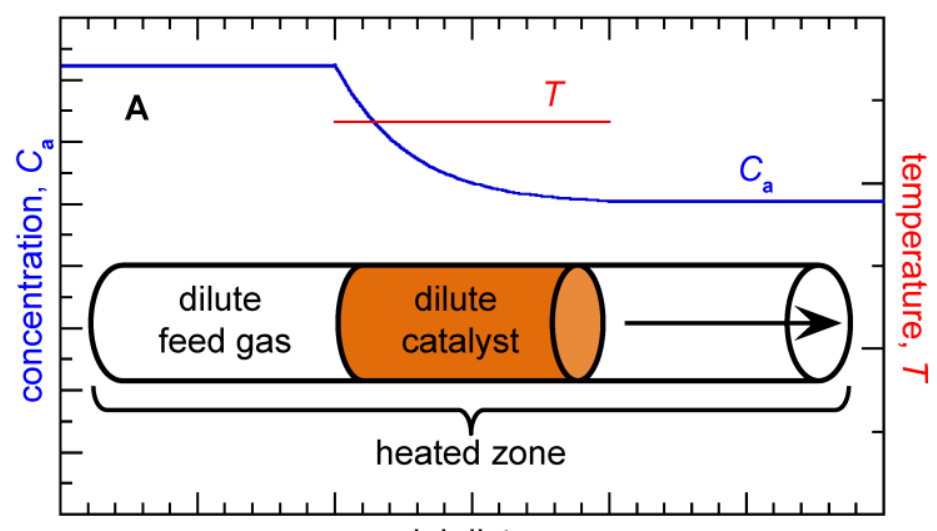

axial distance

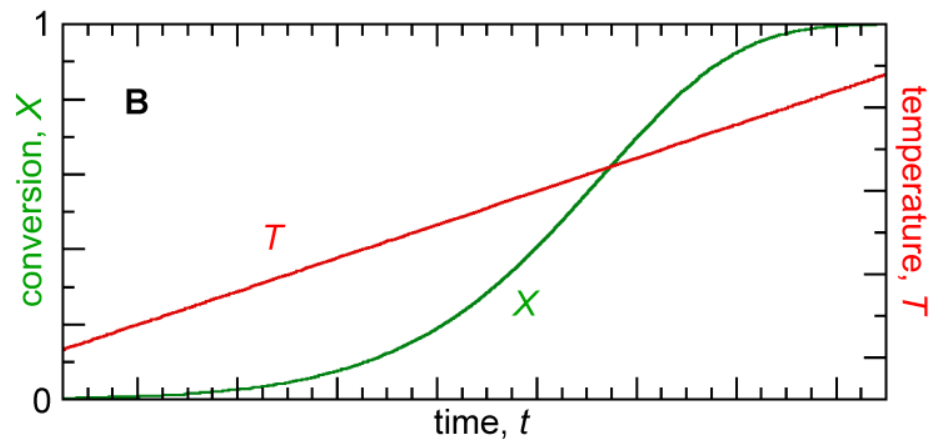

Fig. 1. (A) Reactor scheme for variable-temperature kinetics experiment in a tubular packed-bed reactor. The reactor inlet and outlet as well as the catalyst bed (orange) are heated in a tube furnace. At any given time, the entire reactor temperature is essentially constant, while the concentration of the limiting reactant a decreases as a function of axial distance. (B) The variable-temperature reaction profile is constructed from analysis of the effluent gas while the reactor temperature of the reactor is ramped at constant $d T / d t$.

For reproducibility, each catalyst sample was pre-treated in a flow of the appropriate feed gas for $3 \mathrm{~h}$ at a temperature for which the conversion of the limiting reactant was slightly greater than 0.95 . Reactant gas flow rates were varied using mass flow controllers $\left(3-100 \mathrm{~mL} \mathrm{~min}^{-1}\right)$. A series of reaction profiles was recorded for volumetric flow rates between 25 and $70 \mathrm{~mL} \mathrm{~min}^{-1}$ 
(corresponding to gas-hourly space velocities, GHSV, of $3-9 \times 10^{4} \mathrm{~h}^{-1}$ ), varying in random order. At each flow rate, three reaction profiles were recorded sequentially. For $\mathrm{H}_{2}$ and $\mathrm{C}_{3} \mathrm{H}_{8}$ oxidation, conversion was calculated from the loss of signal intensity for the limiting reactant, $I_{\mathrm{a}}$, Eq. 2, while for $\mathrm{CO}$ oxidation, the yield of the product $\mathrm{CO}_{2}, I_{\mathrm{CO} 2}$, was monitored, Eq. 3 .

$X=\frac{\left(I_{\text {in }}-I_{\text {zero }}\right)-\left(I_{\mathbf{a}}-I_{\text {zero }}\right)}{I_{\text {in }}-I_{\text {zero }}}=\frac{I_{\text {in }}-I_{\mathbf{a}}}{I_{\text {in }}-I_{\text {zero }}}$

$X=\frac{I_{\mathrm{CO}_{2}}-I_{\text {zero }}}{I_{\text {calibration }}-I_{\text {zero }}}$

$I_{\text {zero }}$ corresponds to the signal intensity recorded at full conversion (for $0 \mathrm{ppm}$ ), $I_{\text {in }}$ corresponds to the maximum inlet signal intensity (below the onset of activity), and $I_{\text {calibration }}$ is the signal for the calibration gas $\left(\mathrm{CO}_{2}\right)$ measured at the same flow rate.

\subsection{Minimization of non-kinetic effects}

Heat and mass transfer effects must be negligible to allow for curve-fitting of the analytical VTK equations described below to the reaction profiles, and to ensure that parameters extracted from these profiles are purely kinetic. In order to minimize non-kinetic effects, experiments were conducted with large amounts of inert diluents ( $\mathrm{Ar}, \mathrm{SiC})$ in both the feed gas and in the catalyst bed. The possible contributions of external and internal mass transfer as well as heat transfer to the observed reaction rates are negligible according to Mears' criterion [48], the Weisz-Prater parameter [49], and Mears' heat criterion [50] (see Supplementary Material for sample calculations). 
Possible contributions from non-kinetic effects were also assessed experimentally. Reaction profiles were typically recorded with ca. $11 \mathrm{mg}$ catalyst sieved to $150-180 \mu \mathrm{m}$ and diluted 1:3 with $\mathrm{SiC}$, at a temperature ramp rate of $5 \mathrm{~K} \mathrm{~min}^{-1}$. Reaction profiles for propane oxidation recorded for different reactor loadings of catalyst, while keeping constant the ratio of catalyst mass to volumetric flow rate [48], are nearly superposable (Fig. S1). Rates for propane oxidation did not change with catalyst particle diameter (Fig. S1). Thus external and internal mass transfer rates do not affect the observed reaction rates significantly. The absence of thermal lag due to the heat of reaction was verified experimentally. Reaction profiles for $\mathrm{H}_{2}$ oxidation recorded at temperature ramp rates from $2-7 \mathrm{~K} \mathrm{~min}^{-1}$ resulted in identical $T_{50}$ values and nearsuperposable curves (Fig. S3), attesting to the absence of thermal lag for this reactor configuration. Finally, reaction profiles for propane oxidation were unaffected by the catalyst dilution ratio (Fig. S2).

The use of a temperature ramp rate that is slow relative to the reactor residence time (ca. $0.001 \mathrm{~min}$ ) ensures negligible accumulation of heat due to reaction, so that the catalyst bed remains near-isothermal during each measurement of conversion at a particular reactor temperature. In $\mathrm{CO}$ oxidation at an overall conversion of 0.2 , the measured bed entrance and exit temperatures were the same, $120^{\circ} \mathrm{C}$, within the measurement uncertainty. At full conversion, the bed exit temperature $\left(150{ }^{\circ} \mathrm{C}\right)$ was slightly higher than the entrance temperature $\left(149{ }^{\circ} \mathrm{C}\right)$. Consequently, we assumed that axial temperature gradients were negligible, and that the temperature of the entire bed can be described by a single value measured at the entrance. In a recent series of $\mathrm{CO}$ oxidation experiments conducted using similar conditions (1000 ppm CO, $10 \% \mathrm{O}_{2}$ flowing at $50 \mathrm{~mL} \mathrm{~min}{ }^{-1}$ over undiluted $4 \mathrm{wt} \% \mathrm{Pt} / \mathrm{Al}_{2} \mathrm{O}_{3}$ in a reactor with an inner diameter of $1.7 \mathrm{~mm}$ ), temperatures across the entire catalyst bed were measured directly using IR 
thermography [51]. The maximum difference in local temperatures was only $2{ }^{\circ} \mathrm{C}$. In our experiments, the use of inert diluents for both the feed gas and the catalyst bed are expected to result in even smaller temperature variations [50].

\subsection{Curve-fitting reaction profiles}

Reaction profiles were analyzed individually, as well as simultaneously (i.e., globally), for a series of profiles recorded with different volumetric flow rates, via non-linear least-squares refinement to the kinetic equations described below. Analyses were performed using either Origin (OriginLab) or Kaleidagraph (Synergy Software). Initial parameter guesses for the activation parameters $A$ and $E_{\text {a }}$ were chosen based on previously reported values, and/or values estimated using $(X, T)$ data from the differential region of the reaction profile. The results are not sensitive to changes in these initial values. In individual curve-fits, $A$ and $E_{\mathrm{a}}$ were refined, as well as one or two reaction orders (as specified below). In simultaneous curve-fits to multiple reaction profiles, $E_{\mathrm{a}}$ and the reaction order for each reactant were refined as global fit parameters. Initial values for the reaction orders were chosen based on literature values as well as visual inspection of the shapes of the profiles. Since the pre-exponential term $A$ appears in the curve-fitting equations as the product $A \tau$, where $\tau$ is the varying space-time $(\tau), A \tau$ was refined as a separate parameter for each reaction profile to reduce the impact of experimental error in $\tau$ on refinement of $A$. The reported value of $A$ is the average for all reaction profiles. A curve-fit was judged acceptable if the residuals were random and the refined parameters were physically reasonable. Furthermore, it was possible to truncate experimental reaction profiles to variable extents without significantly changing the values of refined parameters. 
The uncertainty $\sigma_{E a}$ was estimated using full error propagation according to Eq. 4, where $\sigma_{T}$ and $\sigma_{r a}$ are the estimated uncertainties in the temperature and rate, respectively, and $\Delta T$ and $\Delta\left(\ln \left[-r_{\mathbf{a}}\right]\right)$ are the ranges of $T$ and $-r_{\mathrm{a}}$, respectively, used in the analysis [52].

$\left(\sigma_{E_{\mathbf{a}}} / E_{\mathrm{a}}\right)^{2}=2\left(T \sigma_{T} /(T \Delta T)\right)^{2}+2\left(\Delta\left(\ln \left[-r_{\mathbf{a}}\right]\right)^{-2}\left(\sigma_{r \mathbf{a}} /-r_{\mathbf{a}}\right)^{2}\right.$

The uncertainty in $A$ was estimated as the standard deviation of the average for all preexponential values. To estimate the uncertainty in the rate laws with two variable reaction orders, one reaction order was fixed to its refined value while the other was fixed manually above and below its original curve-fitted value until either $E_{\text {a }}$ or $A$ exceeded its predetermined uncertainty.

\subsection{Conventional kinetic analysis}

After all reaction profiles had been recorded under a given set of reaction conditions, the reactor was operated at steady-state for several temperatures corresponding to $0.01<X<0.10$. The reaction rate was calculated using Eq. 1, then $E_{\mathrm{a}}$ was obtained from the slope of an Arrhenius plot constructed using $\ln \left(-r_{\mathbf{a}}\right)$ vs. $T^{-1}$. The uncertainty $\sigma_{A}$ was calculated using error propagation analogous to Eq. 4 (replacing $\sigma_{E \mathrm{a}}$ and $E_{\mathrm{a}}$ by $\sigma_{A}$ and $A$, respectively). Arrhenius plots were also constructed by plotting $\ln (k)$ vs. $T^{-1}$, where $k$ values were calculated according to Eq. 5 below, using appropriate integer reaction orders obtained from the literature. Sample calculations can be found in the Supplementary Material.

\section{Results}

\subsection{Kinetic equations for reaction profiles}


When temperature gradients and mass transfer effects in the catalyst bed are minimal, just three relations are necessary to describe the reaction kinetics for a limiting reactant and $j$ nonlimiting reactants during a variable-temperature kinetics experiment: the reactor design equation, the rate equation, and the Arrhenius equation. They are shown, combined, in Eq. 5.

$C_{\mathbf{a}, 0} v_{0} \frac{d X}{d W}=-r_{\mathbf{a}}=A e^{-\frac{E_{a}}{R T}}\left[C_{\mathbf{a}, 0}(1-X)\right]^{n} \prod_{i}^{j}\left[C_{\mathbf{a}, 0}\left(\Theta_{\mathbf{i}}-X b_{\mathbf{i}} / a\right)\right]^{m_{\mathbf{i}}}$

$C_{\mathbf{a}, 0}$ is the inlet concentration of the limiting reactant; $v_{0}$ is the inlet volumetric flow rate of the feed gas; $a$ and $b_{\mathbf{i}}$ are the stoichiometric coefficients of the limiting reactant $\mathbf{a}$ and each nonlimiting reacting species $\mathbf{i}$, respectively; and $\Theta_{\mathbf{i}}$ is the molar ratio of species $\mathbf{i}$ and $\mathbf{a}$ in the feed gas. The reaction orders with respect to species $\mathbf{a}$ and $\mathbf{i}$ are designated $n$ and $m_{\mathrm{i}}$, respectively.

In favorable cases, Eq. 5 can be integrated and solved for $X$. For example, when the rate law depends on just two reactants, and the ratio of their inlet concentrations $\left(\Theta_{\mathbf{b}}\right)$ is chosen to be equal to the ratio of the stoichiometric coefficients, $b / a$ (such that $\Theta_{\mathbf{b}}$ is independent of conversion), the result is Eq. 6:

$$
X=1-\left[1+(n+m-1)\left(\frac{T_{\mathrm{ref}}}{T}\right)^{n+m}\left(\frac{b}{a}\right)^{m} C_{\mathbf{a}, 0, \mathrm{ref}}^{n+m-1} \tau_{\mathrm{ref}} A e^{-\frac{E_{\mathrm{a}}}{R T}}\right]^{\frac{1}{1-n-m}}
$$

Since the inlet temperature changes during the experiment, inlet reactant concentrations and volumetric flow rates are not constant: $C_{\mathbf{a}, 0}$ and $v_{0}$ are inversely and directly proportional to $T$, respectively. Therefore, both are written in terms of their values at a reference temperature, using 


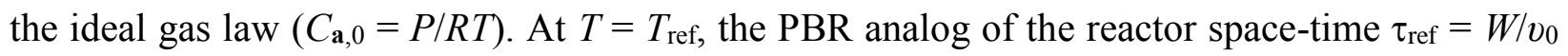
$\left(g_{\text {catalyst }} \mathrm{S} \mathrm{m}^{-3}\right)$.

If the second reactant is present in large excess over the limiting reactant, such that $\left(\Theta_{\mathbf{b}}-X b / a\right) \approx \Theta_{\mathbf{b}}$, Eq. 7 is obtained instead.

$X=1-\left[1+(n-1) \tau_{\mathrm{ref}} C_{\mathbf{a}, 0, \mathrm{ref}}^{n+m-1}\left(\frac{T_{\mathrm{ref}}}{T}\right)^{n+m} \Theta_{\mathbf{b}}^{m} A e^{-\frac{E_{\mathrm{a}}}{R T}}\right]^{\frac{1}{1-n}}$

Even when $\Theta_{\mathbf{b}}$ is not constant, this approximation still works well up to moderate values of $X$ (Fig. S4). When the approximate analytical solution is not sufficiently accurate, a numerical solution to Eq. 7 can be used instead.

Eq. 6 is obviously indeterminate if $n+m=1$ (as is Eq. 7, for $n=1$ ). Fixing the reaction orders at unity in these special (albeit common) cases gives Eq. 8 - 9.

$$
\begin{array}{ll}
X=1-e^{\left[-\tau_{\mathrm{ref}}\left(\frac{T_{\mathrm{ref}}}{T}\right) \Theta_{\mathbf{b}}^{m} A e^{\left.-\frac{E_{\mathbf{a}}}{R T}\right]}\right.} & n+m=1, \Theta_{\mathbf{b}}=b / a ; \text { or } n=1, m=0 \\
X=1-e^{\left[-\tau_{\mathrm{ref}} C_{\mathbf{a}, 0, \mathrm{ref}}^{m}\left(\frac{T_{\mathrm{ref}}}{T}\right)^{m+1}\right.} \Theta_{\mathbf{b}}^{m} A e^{\left.-\frac{E_{\mathbf{a}}}{R T}\right]} & n=1, m \neq 0, \Theta_{\mathbf{b}}>>1
\end{array}
$$

Analytical solutions for other common power rate laws with a single concentration term are shown in Eq. 10 - 12.

$$
X=1-\sqrt{1-\frac{2 \tau_{\text {ref }}}{C_{\mathbf{a}, \mathrm{O}, \mathrm{ref}}^{2}}\left(\frac{T}{T_{\mathrm{ref}}}\right) A e^{-\frac{E_{\mathrm{a}}}{R T}}} \quad n=-1, m=0
$$




$$
\begin{array}{ll}
X=\frac{\tau_{\text {ref }}}{C_{\mathbf{a}, 0, \text { ref }}} A e^{-\frac{E_{\mathrm{a}}}{R T}} & n=0, m=0 \\
X=1-\frac{1}{1+C_{\mathbf{a}, 0, \text { ref }} \tau_{\text {ref }}\left(\frac{T_{\text {ref }}}{T}\right)^{2} A e^{-\frac{E_{\mathrm{a}}}{R T}}} & n=2, m=0
\end{array}
$$

\subsection{Simulated reaction profiles}

Simulations of reaction profiles for kinetically-controlled reactions with rate laws containing a single concentration term (i.e., variable $n ; m=0$ ) are shown in Fig. 2. Information about the rate law is encoded in both the shape of the reaction profile and the concentration dependence of its position along the $T$-axis. First-order (and pseudo-first-order) reactions $(n=1)$ have the familiar sigmoidal shape, in which the increase in conversion accelerates with increasing temperature, then decelerates as the concentration of reactant in most of the catalyst bed approaches zero. The position of the reaction profile is independent of inlet concentration (Eq. 8), because the concentration dependence of the rate law is the same as the concentration dependence of the reactor design equation.

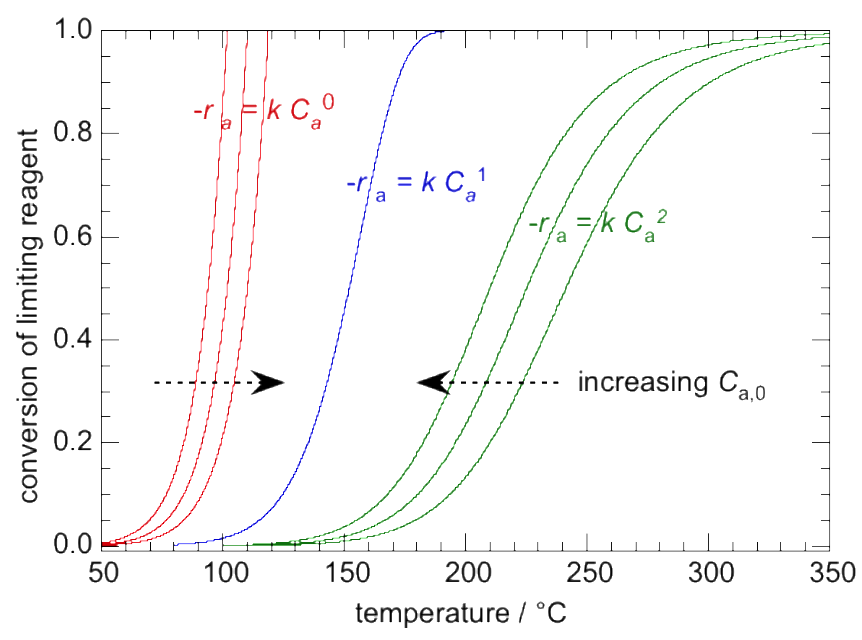

Fig. 2. Reaction profiles simulated using Eqs. 7 - 8 for a reaction with rate law $-r_{\mathbf{a}}=k C_{\mathbf{a}}{ }^{n}$, occurring in a packed-bed reactor. Parameter values: $\tau_{\text {ref }}=1.8 \times 10^{4} \mathrm{~g}_{\text {cat }} \mathrm{s} \mathrm{m}^{-3}, E_{\mathrm{a}}=100 \mathrm{~kJ} \mathrm{~mol}^{-1}$, 


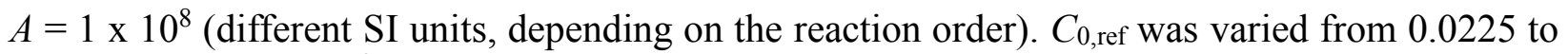
0.045 to $0.090 \mathrm{~mol} \mathrm{~m}^{-3}$, increasing in the direction of the arrows for $n=0$ and 2 .

For overall reaction orders less than 1, deceleration at high conversion due to decreasing reactant concentration is attenuated (indeed, there is no deceleration for $n \leq 0$, and the shape of the profile becomes non-sigmoidal). Increasing $C_{\mathbf{a}, 0}$ displaces the reaction profile to higher temperatures, due to the higher concentration dependence of $X$ in the reactor design equation relative to the rate law. Reaction orders higher than 1 cause the sigmoidal reaction profile to extend over a much wider temperature range. For this case, increasing $C_{\mathbf{a}, 0}$ displaces the profile to lower temperatures.

To aid in visually comparing their shapes, simulated reaction profiles with various reaction orders are aligned at the same $T_{50}$ value in Fig. 3 . The inset to Fig. 3 shows that $T_{50}$ also changes dramatically as the overall reaction order changes, even when all other parameters in Eq. 7 - 8 have the same numerical values. In this example, $T_{50}$ increases from 64 to 101,152 and 225 ${ }^{\circ} \mathrm{C}$ as the order in the limiting reactant changes from -1 to 0,1 and 2 , respectively.

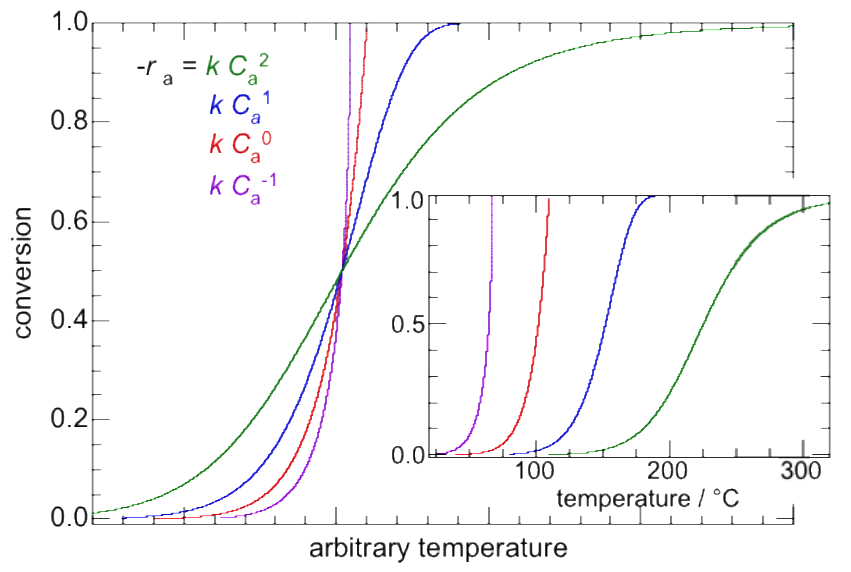

Fig. 3. Reaction profiles simulated with Eqs. 7 - 8 for four rate laws with a single concentration term. Reaction profiles are aligned to a single $T_{50}$ to emphasize differences in shape. The inset 
shows the unaligned reaction profiles. Simulation parameters: $C_{0, \mathrm{ref}} 0.045 \mathrm{~mol} \mathrm{~m}{ }^{-3}, \tau_{\mathrm{ref}}=1.8 \mathrm{x}$ $10^{4} \mathrm{~g}_{\text {cat }} \mathrm{S} \mathrm{m}^{-3}, A=1 \times 10^{8}$ (SI units, varying depending on the reaction order), $E_{\mathrm{a}}=100 \mathrm{~kJ} \mathrm{~mol}^{-1}$.

According to Eq. 8, increasing the catalyst loading and/or decreasing the volumetric flow rate cause the space-time $\tau$ to increase, which decreases the temperature required to achieve a given conversion (e.g., $T_{50}$ ) as shown in Fig. S5. Increasing the Arrhenius pre-exponential factor also shifts the reaction profile to lower temperatures. Since Eq. $6-12$ contain the product $A \tau$, a change in one parameter is indistinguishable from an equivalent change in the other. As expected, changes in $E_{\mathrm{a}}$ have the largest effect on the position of the reaction profile: a $5 \%$ change in the value of $E_{\mathrm{a}}$ causes the same shift in the reaction profile as a 5-fold change in either $A$ or $\tau$. The inescapable conclusion is that $T_{50}$ comparisons are problematic in ranking catalyst activities; the rate law, inlet concentrations, flow rates, and catalyst loading must all be considered.

\subsection{Kinetic parameters obtained from differential steady-state experiments}

Three different catalytic reactions were studied in the presence of a $\mathrm{Pd} / \mathrm{Al}_{2} \mathrm{O}_{3}$ catalyst. In order to validate kinetic parameters for the reactions of $\mathrm{H}_{2}, \mathrm{C}_{3} \mathrm{H}_{8}$, and $\mathrm{CO}$ with $\mathrm{O}_{2}$ obtained by analysis of their variable-temperature reaction profiles (see below) using non-linear curvefitting, we also measured steady-state conversions under differential conditions. Under the conditions of interest here, the rate laws for all three reactions can be represented by a simple power law. Arrhenius plots were constructed using reaction rates (which yield accurate values for $E_{\text {a }}$ only when measured under differential conditions, $X<0.1$, see Supplementary Material). The formulation of the rate law in Eq. 5 reveals a key unstated assumption in the direct use of $X,-r$ a

or TOF to create Arrhenius plots, namely, that all variables other than $k$ (i.e., $F_{\mathbf{a}, 0}$ and $\left.C_{\mathbf{i}}\right)$ are 
temperature-independent. This assumption is indeed reasonable when the conversion is low, since all such terms are approximately constant. In addition, while $E_{\mathrm{a}}$ can always be extracted from the differential Arrhenius slope, the $y$-intercept yields an accurate value for $A$ only with the much stricter condition that $X \approx 0$. Arrhenius plots were also constructed using apparent rate constants (by fixing reaction orders to values obtained in previous studies), in order to obtain physically meaningful values for $A$. The results are shown in Figs. S6-S8 and Table 1.

Table 1. Comparison of apparent Arrhenius parameters extracted by linearization of data from differential, steady-state experiments with those obtained by non-linear curve-fitting of integral, variable-temperature reaction profiles

\begin{tabular}{|c|c|c|c|c|c|c|}
\hline \multirow[t]{2}{*}{ Reaction } & \multirow[t]{2}{*}{$\Theta_{\mathrm{b}}$} & \multicolumn{3}{|c|}{ Steady-state analysis ${ }^{a}$} & \multicolumn{2}{|l|}{ VTK analysis b } \\
\hline & & $\begin{array}{l}\text { Dependent } \\
\text { variable }\end{array}$ & $A$ & $\begin{array}{l}E_{\mathrm{a}} \\
\mathrm{kJ} \mathrm{mol}^{-1}\end{array}$ & $A$ & $\begin{array}{l}E_{\mathrm{a}} \\
\mathrm{kJ} \mathrm{mol}^{-1}\end{array}$ \\
\hline $\mathrm{H}_{2}+1 / 2 \mathrm{O}_{2} \rightarrow \mathrm{H}_{2} \mathrm{O}^{\mathrm{c}}$ & 200 & $-r_{\mathbf{a}}$ & & $58 \pm 6$ & & \\
\hline & & $k$ & $(1.4 \pm 0.1) \times 10^{4}$ & $61 \pm 6$ & $(5 \pm 1) \times 10^{4}$ & $66 \pm 2$ \\
\hline $\begin{aligned} \mathrm{C}_{3} \mathrm{H}_{8} & +5 \mathrm{O}_{2} \\
& \rightarrow 3 \mathrm{CO}_{2}+4 \mathrm{H}_{2} \mathrm{O}^{\mathrm{d}}\end{aligned}$ & 100 & $-r_{\mathbf{a}}$ & & $118 \pm 10$ & & \\
\hline & & $k$ & $(4.5 \pm 0.4) \times 10^{7}$ & $124 \pm 10$ & $(1.0 \pm 0.3) \times 10^{7}$ & $114 \pm 3$ \\
\hline $\mathrm{CO}+1 / 2 \mathrm{O}_{2} \rightarrow \mathrm{CO}_{2}{ }^{\mathrm{e}}$ & 1 & $\begin{array}{l}-r_{\mathrm{a}} \\
k\end{array}$ & $(1.5 \pm 0.1) \times 10^{5}$ & $\begin{array}{l}91 \pm 6 \\
89 \pm 6\end{array}$ & $(3 \pm 2) \times 10^{6}$ & $98 \pm 3$ \\
\hline
\end{tabular}

${ }^{\text {a }}$ Ca. $10 \mathrm{mg} \mathrm{Pd} / \mathrm{Al}_{2} \mathrm{O}_{3}$ diluted 1:3 with $\mathrm{SiC}, v_{0}=50 \mathrm{~mL} \mathrm{~min}^{-1}, 0.01<X<0.10$. Six to nine isothermal measurements were made, covering a temperature range of $25{ }^{\circ} \mathrm{C}$. Uncertainties were obtained by full error propagation similar to Eq. 4.

${ }^{\text {b }}$ Ca. $11 \mathrm{mg} \mathrm{Pd} / \mathrm{Al}_{2} \mathrm{O}_{3}$ diluted 1:3 with $\mathrm{SiC}$. Uncertainties from the standard deviation of the average value for duplicate runs at five different volumetric flow rates (typically, $v_{0}=25-70 \mathrm{~mL} \mathrm{~min}{ }^{-1}$, GHSV $=3.2-8.9 \times 10^{4} \mathrm{~h}^{-1}$ ).

${ }^{c} C_{\mathrm{H} 2,0}=500 \mathrm{ppm}, C_{\mathrm{O} 2,0}=100000 \mathrm{ppm}$. Reaction orders fixed at +1 and 0 for $\mathrm{H}_{2}$ and $\mathrm{O}_{2}$, respectively [45]. Dimensions of $A$ are $\mathrm{m}^{3} \mathrm{~g}_{\mathrm{cat}}{ }^{-1} \mathrm{~s}^{-1}$.

${ }^{\mathrm{d}} C_{\mathrm{C} 3 \mathrm{H} 8,0}=1000 \mathrm{ppm}, C_{\mathrm{O} 2,0}=100000 \mathrm{ppm}$. Reaction orders fixed at +1 and 0 for $\mathrm{C}_{3} \mathrm{H}_{8}$ and $\mathrm{O}_{2}$, respectively [46].

Dimensions of $A$ are $\mathrm{m}^{3} \mathrm{~g}_{\mathrm{cat}}{ }^{-1} \mathrm{~s}^{-1}$.

${ }^{\mathrm{e}} C_{\mathrm{CO}, 0}=1000 \mathrm{ppm}, C_{\mathrm{O} 2,0}=1000 \mathrm{ppm}$. Reaction orders fixed at -1 and +1 for $\mathrm{CO}$ and $\mathrm{O}_{2}$, respectively [47].

Dimensions of $A$ are molco $\mathrm{g}_{\mathrm{cat}}{ }^{-1} \mathrm{~s}^{-1}$.

\subsection{Extracting kinetic parameters from variable-temperature reaction profiles}

\subsubsection{Curve-fitting of individual reaction profiles for $\mathrm{H}_{2}$ oxidation}

Reaction profiles for $\mathrm{H}_{2}$ oxidation catalyzed by $\mathrm{Pd} / \mathrm{Al}_{2} \mathrm{O}_{3}$ were recorded with a large excess of $\mathrm{O}_{2}\left(C_{\mathrm{H} 2,0}=1000 \mathrm{ppm} ; C_{\mathrm{O} 2,0}=100000 \mathrm{ppm}\right)$. At each volumetric flow rate, three 
sigmoidal reaction profiles were recorded, and are superposable (Fig. S9). This finding demonstrates that catalyst deactivation is negligible. For two of the flow rates, the third reaction profile of each series is shown in Fig. 4. Increasing $v_{0}$ from 30 to $70 \mathrm{~mL} \mathrm{~min}^{-1}$ causes $T_{50}$ to increase (Fig. 7), as predicted in section 3.2.

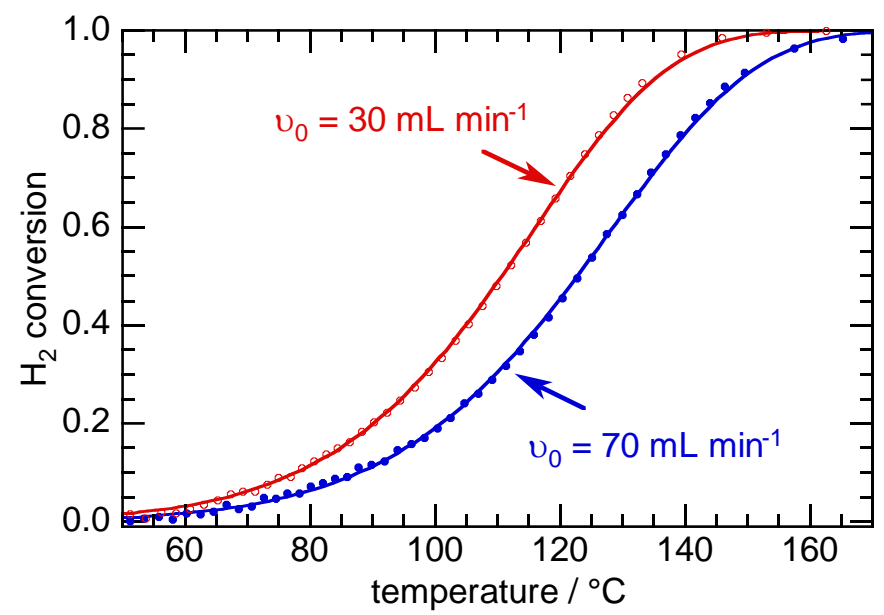

Fig. 4. Representative reaction profiles for $\mathrm{H}_{2}$ oxidation (1000 ppm $\mathrm{H}_{2}, 100000 \mathrm{ppm} \mathrm{O}_{2}$, balance $\mathrm{Ar}$ ) over $\mathrm{Pd} / \mathrm{Al}_{2} \mathrm{O}_{3}(11.4 \mathrm{mg})$ diluted in $\mathrm{SiC}(34.5 \mathrm{mg})$, recorded at flow rates of 30 (open red circles, GHSV $=3.8 \times 10^{4} \mathrm{~h}^{-1}$ ) and $70 \mathrm{~mL} \mathrm{~min}^{-1}$ (solid blue circles, GHSV $=8.9 \times 10^{4} \mathrm{~h}^{-1}$ ). Only one reaction profile (of three recorded) is shown for each flow rate, and every $20^{\text {th }}$ datapoint is displayed (the full set of profiles is shown in Fig. 7). Lines are individual curve-fits of Eq. 8 to the full data range $\left(46 \leq T \leq 195^{\circ} \mathrm{C}\right)$ for a single reaction profile.

The orders of reaction with respect to $\mathrm{H}_{2}$ and $\mathrm{O}_{2}$ are known to be 1 and 0 , respectively [45]. Since $\Theta_{\mathrm{O} 2}=100$, the sigmoidal shape of the reaction profile is determined principally by the positive reaction order with respect to the limiting reactant, $\mathrm{H}_{2}$. As shown above (Fig. 2), the inlet concentration should not affect the position of the reaction profile for a first-order reaction. Indeed, profiles recorded at different inlet $\mathrm{H}_{2}$ concentrations $\left(C_{\mathrm{H} 2,0}=500\right.$ or $\left.1000 \mathrm{ppm}\right)$ have an identical $T_{50}$ values and are virtually superposable (Fig. S11).

For each value of $v_{0}$, Eq. 8 was first curve-fit to a single reaction profile over the entire $X$ $T$ range. Two of the curve-fits are shown superposed on the experimental data in Fig. 4. The 
excellent agreement between the model and the data is readily assessed visually. It confirms that heat and mass transfer effects do not influence the rate over the entire range of conversion. The average values of $E_{\mathrm{a}}$ and $A$ from the individual curve-fits are $(66 \pm 2) \mathrm{kJ} \mathrm{mol}^{-1}$ and $(5 \pm 1) \times 10^{4}$ $\mathrm{m}^{3} \mathrm{~g}_{\text {cat }}{ }^{-1} \mathrm{~s}^{-1}$, respectively. This $E_{\mathrm{a}}$ is similar to a value reported for the oxidation of $1000 \mathrm{ppm}_{2}$ in air, catalyzed by oxide-supported $\mathrm{Pd}$ nanoparticles, $53 \mathrm{~kJ} \mathrm{~mol}^{-1}$ [53]. It also agrees with values determined here in a differential reactor (Table 1), while the value for $A$ differs by a factor of 3.

The amount of data collected in a single, variable-temperature reaction profile is clearly more than sufficient to obtain reliable kinetic parameters. Averaging curve-fit parameters from multiple individual fits did not alter the values significantly. Indeed, essentially the same values were obtained when just $1 \%$ of the data from a single reaction profile (for a total of ten data points, evenly spaced in $X$ ) was used in the curve-fit. The effect of truncating the reaction profile was also explored. For the profile recorded at $v_{0}=40 \mathrm{~mL} \mathrm{~min}^{-1}$, a curve-fit of Eq. 8 using data limited to $X \leq 0.2$ yielded the same $E_{\mathrm{a}}$ value, $(66 \pm 3) \mathrm{kJ} \mathrm{mol}^{-1}$, as did curve-fits to data truncated at other, intermediate conversions.

It is not uncommon for spurious correlations between $E_{\mathrm{a}}$ and $A$ to appear in kinetic analyses, because of their very different magnitudes and non-linear relationship [54]. The correlation can be minimized by temperature-centering, in which a reference rate constant, $k_{0}$, is defined at a temperature $T_{0}$ relevant to the reaction conditions, Eq. $13[12,55]$. While Eq. 13 is mathematically equivalent to the usual Arrhenius relationship for $k$, it has the potential benefits of reducing the search space for the pre-exponential factor, as well as minimizing correlations between $A$ and $E_{a}$.

$k=k_{0} \exp \left[-\frac{E_{\mathrm{a}}}{R}\left(\frac{1}{T}-\frac{1}{T_{0}}\right)\right]=A \exp \left(-\frac{E_{\mathrm{a}}}{R T_{0}}\right) \exp \left[-\frac{E_{\mathrm{a}}}{R}\left(\frac{1}{T}-\frac{1}{T_{0}}\right)\right]$ 
When this formulation for the rate constant was used to modify Eq. 8, and $k_{0}$ and $E_{\text {a }}$ were refined in a curve-fit to the data in Fig. 4, the resulting kinetic parameters were indistinguishable from those obtained using Eq. 8 directly, suggesting that the non-linear analysis method does not generate inherently correlated activation parameters.

The reaction orders were also studied as variable curve-fit parameters using Eq. 7. The results are shown in Fig. S12. The corresponding average values of $E_{\mathrm{a}}$ and $A$ are essentially unchanged, at $(61 \pm 2) \mathrm{kJ} \mathrm{mol}^{-1}$ and $(9.1 \pm 0.3) \times 10^{3} \mathrm{~m}^{3} \mathrm{~g}_{\mathrm{cat}}{ }^{-1} \mathrm{~s}^{-1}$, respectively. The average fitted reaction orders with respect to $\mathrm{H}_{2}$ and $\mathrm{O}_{2}$ are $(0.9 \pm 0.1)$ and $(-0.2 \pm 0.5)$, respectively. Similar fit parameters were obtained at each flow rate.

\subsubsection{Curve-fitting of individual reaction profiles for propane oxidation}

Reaction profiles for propane oxidation catalyzed by $\mathrm{Pd} / \mathrm{Al}_{2} \mathrm{O}_{3}$ were recorded in a similar fashion, with a large excess of $\mathrm{O}_{2}\left(C_{\mathrm{C} 3 \mathrm{H} 8,0}=1000\right.$ ppm; $C_{\mathrm{O} 2,0}=100000$ ppm $)$. According to Fig. 5, their sigmoidal shape signals that the rate law has a positive reaction order for the limiting reactant, propane. As expected, the reaction profile shifts to higher temperatures with increasing volumetric flow rate. Compared to profiles for $\mathrm{H}_{2}$ oxidation, the $T_{50}$ values for propane oxidation are far higher (at the same concentrations and flow rate), consistent with an activation energy for propane oxidation that is approximately twice as large. 


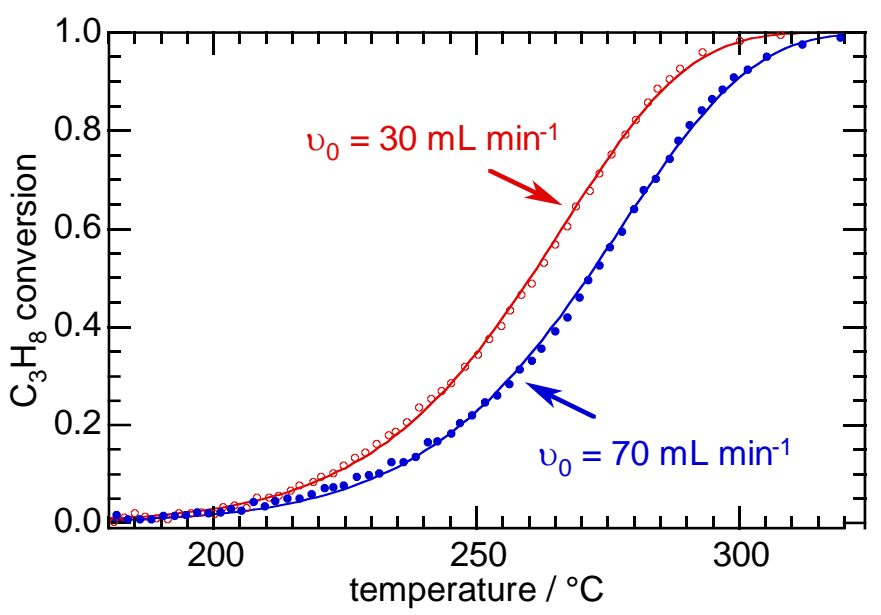

Fig. 5. Representative reaction profiles for propane oxidation (1000 ppm $\mathrm{C}_{3} \mathrm{H}_{8}, 100000 \mathrm{ppm} \mathrm{O}_{2}$, balance $\mathrm{Ar}$ ) over $\mathrm{Pd} / \mathrm{Al}_{2} \mathrm{O}_{3}(11.8 \mathrm{mg})$ diluted in $\mathrm{SiC}(30.9 \mathrm{mg})$, recorded at flow rates of 40 (hollow red circles, GHSV $=5.1 \times 10^{4} \mathrm{~h}^{-1}$ ) and $60 \mathrm{~mL} \mathrm{~min}^{-1}$ (solid blue circles, GHSV $=7.6 \mathrm{x}$ $10^{4} \mathrm{~h}^{-1}$ ). Only one reaction profile is shown for each flow rate (of two recorded), and every $100^{\text {th }}$ datapoint is shown (the full set of profiles is shown in Fig. 8). Lines are individual curve-fits of Eq. 8 to the full data range, $180 \leq T \leq 350^{\circ} \mathrm{C}$.

Curve-fits of individual reaction profiles using the entire temperature/conversion range were obtained using Eq. 8. The resulting average values of $E_{\mathrm{a}}$ and $A$, $(114 \pm 3) \mathrm{kJ} \mathrm{mol}^{-1}$ and $(1.0$ $\pm 0.3) \times 10^{7} \mathrm{~m}^{3} \mathrm{~g}_{\mathrm{cat}}{ }^{-1} \mathrm{~s}^{-1}$, respectively, agree well with the values from differential steady-state measurements in Table 1. The activation energy is close to the high end of the range of values reported for propane oxidation in $\mathrm{O}_{2}$-rich conditions catalyzed by $\mathrm{Pd}$ foil, wire and nanoparticles supported on $\gamma-\mathrm{Al}_{2} \mathrm{O}_{3}$, typically $60-100 \mathrm{~kJ} \mathrm{~mol}^{-1}$ [46, 56, 57]. Curve-fits obtained using Eq. 7 instead yielded average values for $E_{\mathrm{a}}$ and $A$ of $(107 \pm 4) \mathrm{kJ} \mathrm{mol}^{-1}$ and $(1.4 \pm 0.3) \times 10^{6} \mathrm{~m}^{3} \mathrm{~g}_{\mathrm{cat}}^{-1} \mathrm{~s}^{-}$ ${ }^{1}$, respectively, as well as reaction orders of $(0.9 \pm 0.1)$ and $(-0.5 \pm 0.8)$ with respect to propane and $\mathrm{O}_{2}$, respectively.

\subsubsection{Curve-fitting of individual reaction profiles for $\mathrm{CO}$ oxidation}


Reaction profiles for $\mathrm{CO}$ oxidation with equimolar reactant concentrations $\left(C_{\mathrm{CO}, 0}=C_{\mathrm{O} 2,0}\right.$ $=1000 \mathrm{ppm}$ ) catalyzed by $\mathrm{Pd} / \mathrm{Al}_{2} \mathrm{O}_{3}$ were recorded at volumetric flow rates from 25 to $50 \mathrm{~mL}$ $\min ^{-1}$. Under these conditions, the rate law is expected to be close to zeroth-order overall (since the orders of reaction are +1 and -1 with respect to $\mathrm{O}_{2}$ and $\mathrm{CO}$, respectively). Two representative profiles are shown in Fig. 6. The profiles shift to higher temperatures as the volumetric flow rate increases, as predicted in Fig. 2. The rate of increase in activity accelerates with increasing temperature over nearly the entire temperature range. Such behavior is predicted qualitatively by the simulated zeroth-order reaction profile in Fig. 3. At the lowest volumetric flow rate $(25 \mathrm{~mL}$ $\min ^{-1}$ ), the rate continues to accelerate nearly to $X=1$. At higher flow rates, deceleration at $X>$ 0.85 results in a sigmoidal appearance.

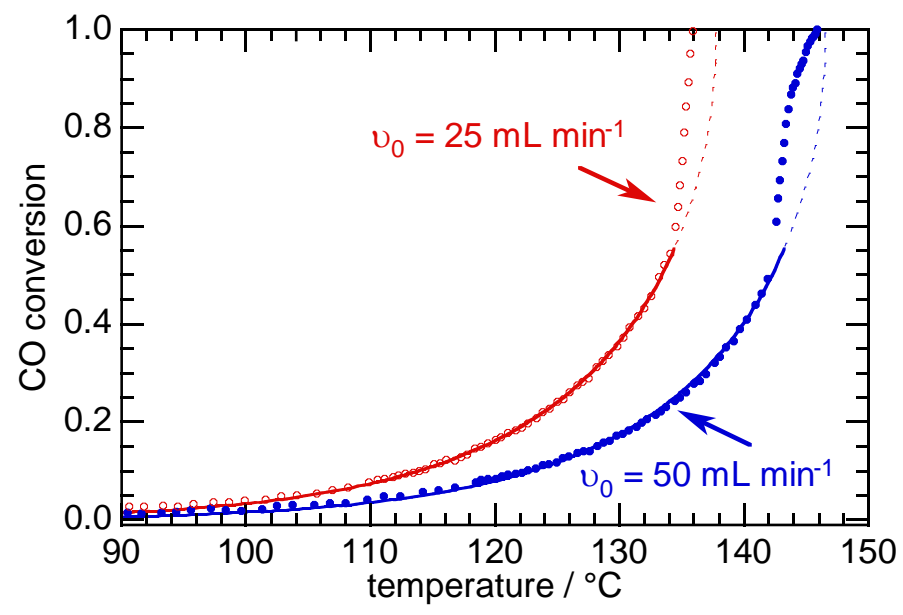

Fig. 6. Representative reaction profiles for $\mathrm{CO}$ oxidation $\left(1000 \mathrm{ppm} \mathrm{CO}_{2}, 1000 \mathrm{ppm} \mathrm{O}_{2}\right.$, balance Ar) over $\mathrm{Pd} / \mathrm{Al}_{2} \mathrm{O}_{3}(11.3 \mathrm{mg})$ diluted in $\mathrm{SiC}(35.4 \mathrm{mg})$, recorded at flow rates of 25 (open red circles, GHSV $=3.2 \times 10^{4} \mathrm{~h}^{-1}$ ) and $50 \mathrm{~mL} \mathrm{~min}^{-1}$ (solid blue circles, GHSV $=6.3 \times 10^{4} \mathrm{~h}^{-1}$ ). Only one reaction profile (of three recorded) is shown for each flow rate, and approx. one-third of the data recorded is displayed (the full set of profiles is shown in Fig. 9). Individual curve-fits of Eq. 7 are shown for fixed values of $n=-1$ and $m=1$, and $0 \leq X \leq 0.6$ (solid lines). Dashed lines show curve-fits extrapolated for $0.6<X \leq 1$. 
Prior to curve-fitting with Eq. 7, each reaction profile was truncated at $X=0.6$ to avoid possible complications from mass and/or heat transfer limitations, as well as changes in the surface chemistry, which can alter the observed rate law. In addition, the use of Eq. 7 is not justified for $X>0.6$, where the analytical and numerical solutions differ for $\Theta_{\mathrm{O} 2} \approx b / a$. Further truncation (i.e., below $X=0.6$ ) did not affect the fit parameters. Representative curve-fits, with fixed reaction orders of -1 and +1 with respect to $\mathrm{CO}$ and $\mathrm{O}_{2}$, to the individual truncated reaction profiles are shown in Fig. 6. The average values for $E_{\mathrm{a}}$ and $A$ obtained from fits at all flow rates are $(98 \pm 3) \mathrm{kJ} \mathrm{mol}^{-1}$ and $(3 \pm 2) \times 10^{6} \mathrm{~mol} \mathrm{~g}_{\mathrm{cat}}{ }^{-1} \mathrm{~s}^{-1}$, respectively. (Fixing the reaction order with respect to $\mathrm{O}_{2}$ instead at +0.5 , implying dissociative chemisorption of $\mathrm{O}_{2}$, barely changes these results.) The value of $E_{\mathrm{a}},(96 \pm 4) \mathrm{kJ} \mathrm{mol}^{-1}$, and the refined value of $A$, $(3 \pm 2) \times 10^{5} \mathrm{~mol}^{3 / 2} \mathrm{~g}_{\text {cat }}{ }^{-1}$ $\mathrm{s}^{-1} \mathrm{~m}^{-3 / 2}$, agree with those obtained by differential analysis (Table 1 ).

When the individual curve-fits were repeated using Eq. 7 and variable reaction orders $n$ and $m$, the average values obtained were $(-1.7 \pm 0.5)$ and $(2.2 \pm 1.7)$, respectively. While the average sum $(n+m)$ is $(0.5 \pm 2.2)$, which is indistinguishable from the expected value $(0)$, the uncertainty is very large. The opposing reaction orders in the rate law, in combination with the choice of equimolar inlet concentrations, together make it particularly difficult to distinguish $n$ and $m$ in the curve-fit of a single reaction profile. Therefore, global curve-fitting was explored to determine whether more reliable rate law information for complex rate laws can be obtained in this way.

\subsection{Global curve-fitting of variable-temperature reaction profiles}

\subsubsection{Simultaneous analysis of $\mathrm{H}_{2}$ oxidation profiles}


The global fit of Eq. 7 to the set of ten $\mathrm{H}_{2}$ oxidation profiles (two profiles recorded consecutively at each of five different values of $v_{0}$ ) is shown in Fig. 7. The activation energy and reaction orders were refined as global variables. The global fit reproduces the shape and position of each reaction profile. The resulting activation energy is $(61 \pm 2) \mathrm{kJ} \mathrm{mol}^{-1}$, while the average value of $A$ is $(8.4 \pm 0.9) \times 10^{3} \mathrm{~m}^{3} \mathrm{~g}_{\mathrm{cat}}^{-1} \mathrm{~s}^{-1}$, Table 2 . The agreement with $E_{\mathrm{a}}$ values from differential, steady-state analysis, as well as with values obtained by curve-fitting individual reaction profiles (Table 1), is excellent.

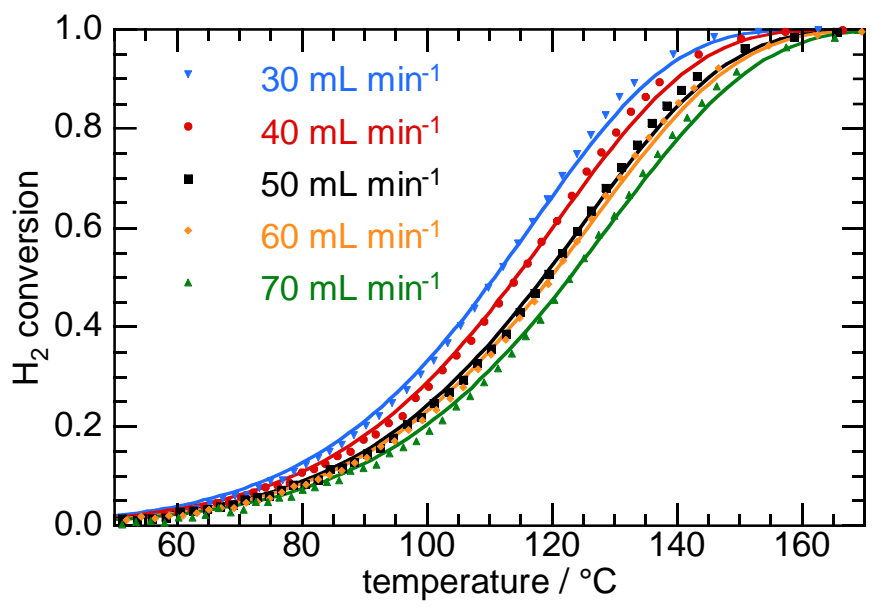

Fig. 7. Reaction profiles (symbols) for $\mathrm{H}_{2}$ oxidation (1000 $\mathrm{ppm}_{2}, 100000 \mathrm{ppm} \mathrm{O}_{2}$, balance Ar) over $\mathrm{Pd} / \mathrm{Al}_{2} \mathrm{O}_{3}(11.4 \mathrm{mg}$ ) diluted in $\mathrm{SiC}(34.5 \mathrm{mg})$. Only one reaction profile (of three recorded) is shown for each flow rate (GHSV $=3.8-8.9 \times 10^{4} \mathrm{~h}^{-1}$ ), and every $20^{\text {th }}$ datapoint is displayed. Lines are global curve-fits of Eq. 7 to the full data range $\left(46{ }^{\circ} \mathrm{C} \leq T \leq 195{ }^{\circ} \mathrm{C}\right)$ for every reaction profile. $E_{\mathrm{a}}, n$, and $m$ were refined as global parameters. The pre-exponential factor $A$ was refined separately for each profile.

The globally-refined values for the reaction orders with respect to $\mathrm{H}_{2}$ and $\mathrm{O}_{2},(0.9 \pm 0.1)$ and $(-0.3 \pm 0.4)$, respectively, are unchanged from the values obtained in the individual curvefits. The corresponding activation parameters are shown in Table 2. Fixing the reaction order with respect to $\mathrm{O}_{2}$ to an integer value (i.e., $m=-1,0$ or 1 ) did not cause the refined value of $E_{\text {a }}$ to 
change significantly. When fixed at the reported value $(m=0)$, the global fit of Eq. 7 gave a refined $E_{\mathrm{a}}$ value of $(61.2 \pm 1.8) \mathrm{kJ} \mathrm{mol}^{-1}$, an average pre-exponential factor of $(7.0 \pm 0.8) \times 10^{3}$ $\mathrm{m}^{3} \mathrm{~g}_{\mathrm{cat}}{ }^{-1} \mathrm{~s}^{-1}$, and a reaction order with respect to $\mathrm{H}_{2}$ of $(0.9 \pm 0.1)$.

Table 2. Apparent Arrhenius parameters and reaction orders extracted from global curve-fits ${ }^{\mathrm{a}}$ of Eq. 7 to reaction profiles

\begin{tabular}{llllll}
\hline Reaction & $\Theta_{\mathbf{b}}$ & $\boldsymbol{A}$ & $\boldsymbol{E}_{\mathbf{a}} / \mathbf{k J ~ m o l}^{\mathbf{1}}$ & $\boldsymbol{n}$ & $\boldsymbol{m}$ \\
\hline $\mathrm{H}_{2}+1 / 2 \mathrm{O}_{2} \rightarrow \mathrm{H}_{2} \mathrm{O}^{\mathrm{b}}$ & 100 & $(8.4 \pm 0.9) \times 10^{3}$ & $61 \pm 2$ & $0.9 \pm 0.1$ & $-0.3 \pm 0.4$ \\
$\mathrm{C}_{3} \mathrm{H}_{8}+5 \mathrm{O}_{2} \rightarrow 3 \mathrm{CO}_{2}+4 \mathrm{H}_{2} \mathrm{O}^{\mathrm{c}}$ & 100 & $(2.7 \pm 0.4) \times 10^{6}$ & $110 \pm 3$ & $0.9 \pm 0.1$ & $0.2 \pm 0.3$ \\
$\mathrm{CO}+1 / 2 \mathrm{O}_{2} \rightarrow \mathrm{CO}_{2}{ }^{\mathrm{d}}$ & 1 & $(1.5 \pm 0.4) \times 10^{5}$ & $91 \pm 6$ & $-1.1 \pm 0.1$ & $0.8 \pm 0.2$ \\
\hline
\end{tabular}

${ }^{a} \mathrm{Ca} .11 \mathrm{mg} \mathrm{Pd} / \mathrm{Al}_{2} \mathrm{O}_{3}$ diluted 1:3 with SiC. Uncertainties in $A$ are the standard deviation of the average value for duplicate runs at five different volumetric flow rates (typically, $v_{0}=25-70 \mathrm{~mL} \mathrm{~min}^{-1}$, GHSV $=3.2-8.9 \times 10^{4} \mathrm{~h}^{-1}$ ). Uncertainties in $E_{\mathrm{a}}$ were obtained by full error propagation using Eq. 4.

${ }^{\mathrm{b}} C_{\mathrm{H} 2,0}=1000 \mathrm{ppm}, C_{\mathrm{O} 2,0}=100000 \mathrm{ppm}$. Dimensions of $A \operatorname{are~m}^{3} \mathrm{~g}_{\mathrm{cat}}{ }^{-1} \mathrm{~s}^{-1}$.

${ }^{\mathrm{c}} C_{\mathrm{C} 3 \mathrm{H} 8,0}=1000 \mathrm{ppm}, C_{\mathrm{O} 2,0}=100000 \mathrm{ppm}$. Dimensions of $A$ are $\mathrm{m}^{3} \mathrm{~g}_{\mathrm{cat}}{ }^{-1} \mathrm{~s}^{-1}$.

${ }^{\mathrm{d}} C_{\mathrm{CO}, 0}=1000 \mathrm{ppm}, C_{\mathrm{O} 2,0}=1000 \mathrm{ppm}$. Dimensions of $A$ are mol $_{\mathrm{CO}} \mathrm{g}_{\mathrm{cat}}{ }^{-1} \mathrm{~s}^{-1}$.

\subsubsection{Simultaneous analysis of propane oxidation profiles}

A similar approach was used for propane oxidation, by simultaneous curve-fitting of Eq. 7 to ten reaction profiles (two superposable profiles recorded at each flow rate over the entire data range, $180-320{ }^{\circ} \mathrm{C}$ ), with $E_{\mathrm{a}}, n$ and $m$ as global variables (Fig. 8). The resulting activation energy is $(110 \pm 3) \mathrm{kJ} \mathrm{mol}^{-1}$, while the average value of $A$ is $(2.7 \pm 0.4) \times 10^{6} \mathrm{~m}^{3} \mathrm{gcat}^{-1} \mathrm{~s}^{-1}$. The reaction order for propane refines to $n=(0.9 \pm 0.1)$, while the reaction order in $\mathrm{O}_{2}$ refines to $m=$ $(0.2 \pm 0.3)$, in agreement with the literature value (0) [46]. The values of $E_{\mathrm{a}}$ and $n$ agree with values obtained from differential steady-state analysis and variable-temperature analysis of individual reaction profiles, while the value of $A$ is an order of magnitude smaller. Repeating the global fit while fixing the reaction order with respect to $\mathrm{O}_{2}$ at zero did not affect the values of $E_{\mathrm{a}}$, $A$, or $n$. 


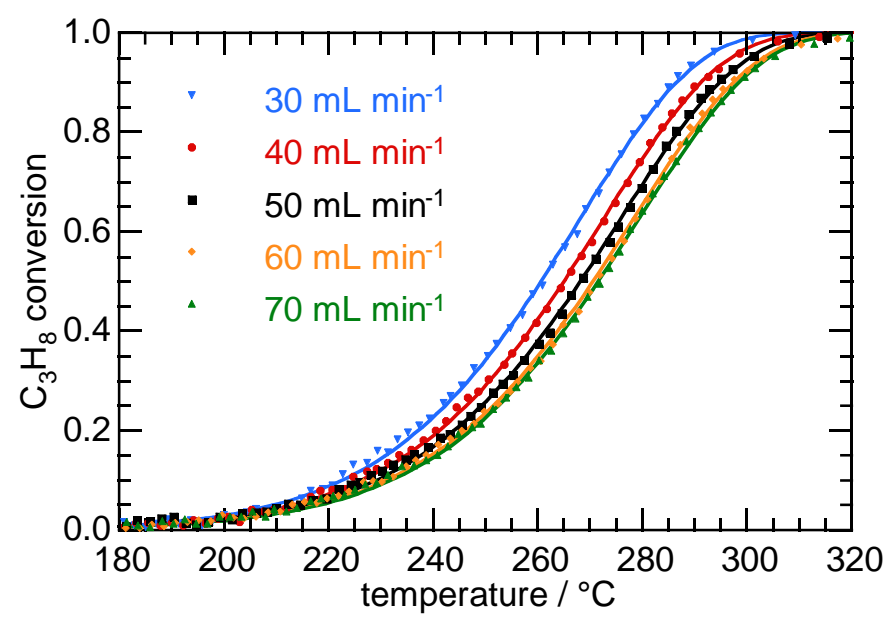

Fig. 8. Reaction profiles (symbols) for $\mathrm{C}_{3} \mathrm{H}_{8}$ oxidation (1000 ppm $\mathrm{C}_{3} \mathrm{H}_{8}, 100000$ ppm $\mathrm{O}_{2}$, balance $\mathrm{Ar}$ ) over $\mathrm{Pd} / \mathrm{Al}_{2} \mathrm{O}_{3}(11.8 \mathrm{mg}$ ) diluted in $\mathrm{SiC}(30.9 \mathrm{mg})$. Only one reaction profile (of three recorded) is shown for each flow rate $\left(\mathrm{GHSV}=3.8-8.9 \times 10^{4} \mathrm{~h}^{-1}\right)$, and every $100^{\text {th }}$ datapoint is displayed. Lines are global curve-fits of Eq. 7 to the full data range $\left(180{ }^{\circ} \mathrm{C} \leq T \leq\right.$ $350{ }^{\circ} \mathrm{C}$ ) for every reaction profile. $E_{\mathrm{a}}, n$, and $m$ were refined as global parameters. The preexponential factor $A$ was refined separately for each profile.

\subsubsection{Simultaneous analysis of $C O$ oxidation profiles}

The simultaneous fit of Eq. 7 to ten reaction profiles, each truncated at $X=0.6$, was conducted as described above, with refinement of both reaction orders $n$ and $m$. The results are shown in Fig. 9. The activation energy $E_{\mathrm{a}},(93 \pm 3) \mathrm{kJ} \mathrm{mol}^{-1}$, and the average value for the preexponential factor, $(1.5 \pm 0.4) \times 10^{5}$ molco $_{\mathrm{cat}}{ }^{-1} \mathrm{~s}^{-1}$, are the same as the values in Table 1. In addition, both refined reaction orders, $(-1.1 \pm 0.1)$ and $(0.8 \pm 0.2)$ with respect to $\mathrm{CO}$ and $\mathrm{O}_{2}$, respectively, are consistent with literature values [47]. 


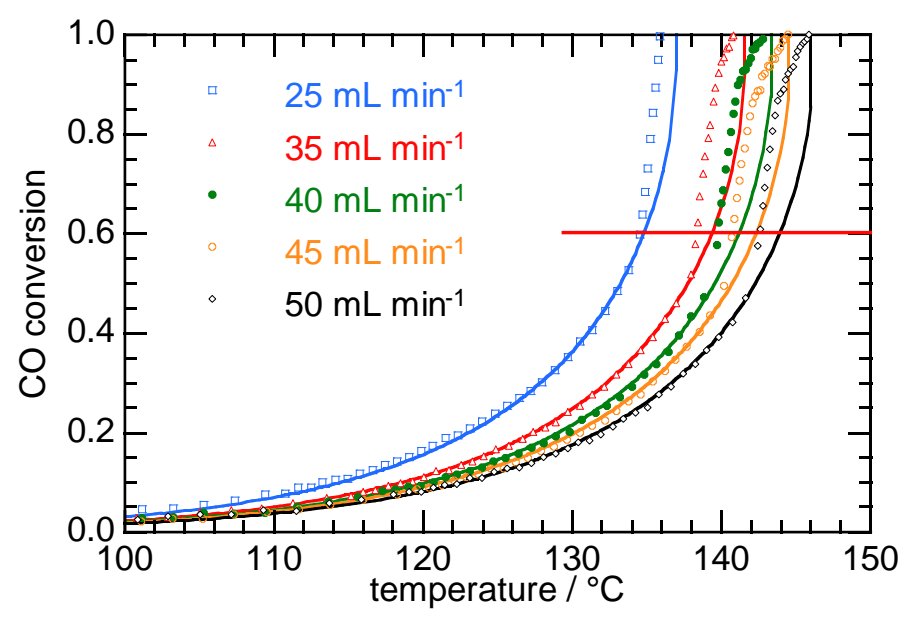

Fig. 9. Reaction profiles (symbols) for $\mathrm{CO}$ oxidation (1000 ppm $\mathrm{CO}, 1000 \mathrm{ppm} \mathrm{O}_{2}$, balance Ar) over $\mathrm{Pd} / \mathrm{Al}_{2} \mathrm{O}_{3}(11.3 \mathrm{mg})$ diluted in $\mathrm{SiC}(35.4 \mathrm{mg})$. Only one reaction profile (of three recorded) is shown for each flow rate $\left(\mathrm{GHSV}=3.2-6.3 \times 10^{4} \mathrm{~h}^{-1}\right)$, and approx. one-third of the data recorded is displayed. Lines are global curve-fits of Eq. 7 (solid lines) to data up to $X=0.6$ (horizontal red line). $E_{\mathrm{a}}, n$, and $m$ were refined as global parameters. The pre-exponential factor $A$ was refined separately for each profile.

\section{Discussion}

\subsection{Qualitative rate law information encoded in individual reaction profiles}

Bimolecular surface reactions generally follow Langmuir-Hinshelwood-type mechanisms, and give rise to rate laws with large numbers of adjustable parameters. Their precise formulation remains an open topic for discussion even in nominally simple systems, such as $\mathrm{CO}$ oxidation over noble metal catalysts [58, 59]. Fortunately, adsorption/desorption phenomena are often rapid relative to surface reactions over the range of conditions sampled in a single reaction profile, making it possible to describe the rate using a simple power law, as shown in Eq. 5.

The shape of the reaction profile conveys qualitative information about the reaction order with respect to the limiting reactant. Reaction orders $n \geq 1$ give rise to sigmoidal profiles (as in the oxidations of $\mathrm{H}_{2}$ and $\mathrm{C}_{3} \mathrm{H}_{8}$ ), while reaction orders $n<1$ give rise to profiles in which the 
conversion increases rapidly with temperature in a non-sigmoidal fashion (as seen for the oxidation of $\mathrm{CO}$ [47]). The precise reaction order can be determined either by refining the value of $n$ in a curve-fit for which $n$ is an adjustable parameter (Eq. 6 or 7), or by the agreement between the model and the data in a curve-fit using a particular integer value for $n$ (Eq. $8-12$ ). Where mass transfer limitations, changes in the rate law, or changes in the surface chemistry are suspected, or the choice of reactant concentrations (e.g., resulting in a significant axial gradient in $\left.\Theta_{b}\right)$ requires it, the dataset can be truncated to remove affected regions (typically, at high conversion). Reactions with $n<1$ appear to be more susceptible to these phenomena due to the rapid rate acceleration as $X$ approaches unity. Conversely, when the kinetic model describes the entire dataset up to $X \approx 1$, this is strong evidence that the rate is not influenced by mass or heat transport.

When a reactant is present in large excess over the limiting reactant (as is the case here for $\mathrm{O}_{2}$ in the oxidation of $\mathrm{H}_{2}$ and propane), its order in the rate law cannot be determined accurately from a single reaction profile. This is expected, due to the relative insensitivity of the profile to the order with respect to a concentration that is essentially constant throughout the catalyst bed under all reaction conditions used. A less common situation arises when reactants are present in similar concentrations and have opposing reaction orders (e.g., -1 and +1 for $\mathrm{CO}$ and $\mathrm{O}_{2}$, respectively). Since their concentrations in the experiment vary in parallel, and their kinetic contributions largely cancel each other, determining the reaction orders requires more than a single reaction profile.

\subsection{Quantitative kinetic parameters from individual reaction profiles}


Arrhenius plots based on kinetic data collected isothermally at steady-state are routinely used to determine activation parameters for heterogeneous catalysts, but the uncertainty in the activation energy is relatively high due to the small number of data points (typically, less than 10) as well as the limited temperature range (typically, $\leq 40 \mathrm{~K}$, as in this study). In addition, the rate law is not assessed and thus the pre-exponential factor cannot be determined without a considerable number of additional isothermal experiments. In contrast, high quality variabletemperature kinetic data can be collected quickly over a wide temperature range in less than an hour (e.g., 400 data points over $110 \mathrm{~K}$ for $\mathrm{CO}$ oxidation, and 6000 data points over $170 \mathrm{~K}$ for $\mathrm{C}_{3} \mathrm{H}_{8}$ oxidation) and its analysis provides all of the desired information, provided care is taken to ensure that mass and energy transport effects are minimized. Consecutive profiles can be used to probe catalyst stability. No special equipment or sophisticated data analysis is required, beyond a thermally-controlled packed bed reactor and a non-linear least squares fitting routine. Remarkably, identical fit results were obtained even when only 10 data points ranging from low to high conversion were analyzed.

In all three cases examined here, the activation energies obtained from a single reaction profile are indistinguishable from those measured in a series of differential steady-state experiments. Furthermore, the larger range of temperatures sampled in the variable-temperature experiment yields the activation energy with somewhat higher precision compared to the conventional Arrhenius analysis. Values for the pre-exponential factors are close, although not identical. Since propane oxidation is much more exothermic than $\mathrm{H}_{2}$ oxidation, and has a much larger activation energy, it represents a more challenging test for reaction profile analysis. Nevertheless, the strong agreement between the differential and variable-temperature results, and 
between the reaction profile data and the model, confirm that the heat of reaction does not influence the measurement of the kinetic parameters.

$\mathrm{CO}$ oxidation is another challenging test of the general utility of variable-temperature reaction profiles. Since the rate law is inverse-first-order with respect to CO [47], the rate increases rapidly with conversion, causing non-kinetic effects to become severe. The reaction profiles in Fig. 6 appear to become mass transfer-limited at moderate-to-high conversions, although deviations from the extrapolated kinetic profiles could also be caused by changes in the rate law and/or the catalyst. Discontinuities may also arise from multiple steady states, which have been observed for $\mathrm{CO}$ oxidation over $\mathrm{Pt} / \mathrm{Al}_{2} \mathrm{O}_{3}[60]$. When such effects distort the data, truncation may be necessary to obtain accurate kinetic parameters. For both $\mathrm{H}_{2}$ and propane oxidation, truncating the datasets did not affect the activation parameters. For $\mathrm{CO}$ oxidation, the extent of truncation below $X=0.6$ did not affect the activation parameters.

\subsection{Conversion-dependent changes in kinetic parameters}

Even without a change in the rate law or the intrusion of non-kinetic effects, the ability to analyze variable-temperature reaction profiles may be impacted by large changes in activation parameters as a function of the reaction conditions. For example, the range of activation energies reported for $\mathrm{CO}$ oxidation catalyzed by supported Pd nanoparticles is very large $\left(54-133 \mathrm{~kJ} \mathrm{~mol}^{-}\right.$ $\left.{ }^{1}\right)$ [61-64]; a similarly large range has been reported for Pd single crystals $\left(60-138 \mathrm{~kJ} \mathrm{~mol}^{-1}\right)$ [47, $61,65]$. Much of the variation is due to the dominant contribution to the activation energy made by the $\mathrm{CO}$ desorption energy [61], which is strongly coverage-dependent due to lateral interactions between adsorbed $\mathrm{CO}$ molecules [66, 67]. For $\mathrm{Pd}(111)$ terraces, the initial heat of adsorption is $149 \mathrm{~kJ} \mathrm{~mol}^{-1}$, while for Pd nanoparticles less than $10 \mathrm{~nm}$ in size, reported initial 
values vary from 106-126 kJ mol ${ }^{-1}$ [68]. For Pd surfaces saturated with $\mathrm{CO}$, the adsorption energy is much smaller, $60-90 \mathrm{~kJ} \mathrm{~mol}^{-1}$ [68-70]. The heat of adsorption on Pd nanoparticles is a strong function of coverage well below 0.6 monolayers, and levels off at high coverage [68]. It also appears to be fairly independent of particle size, for particles larger than $1.5 \mathrm{~nm}[71]$.

Such coverage dependence could make the refinement of an "average" activation energy problematic. Fortunately, variable activation energies do not seem to be a problem here. In our experiments, the $\mathrm{CO}$ coverage is expected to remain high over virtually the entire $P_{\mathrm{CO}}(1000-$ $400 \mathrm{ppm}$ ) and $T\left(90-142{ }^{\circ} \mathrm{C}\right.$ ) ranges used in curve-fitting (corresponding to $0.05 \leq X \leq 0.60$ ) [72]. Consequently, we do not expect the kinetic parameters to vary significantly with conversion in the analysis of individual reaction profiles. This expectation is borne out by the ability of a model containing a single activation energy to describe the profiles very well.

\subsection{Global analysis of multiple variable-temperature reaction profiles}

Uncertainties and correlations in curve-fit parameters can be minimized by performing a global (simultaneous) fit of multiple reaction profiles, recorded with varying $\tau$ values. A similar approach has been used in kinetic analysis of TGA data (using multiple profiles recorded at different heating rates) [73]. In the cases examined here, global curve-fits gave the same activation parameters as individual curve-fits, and uncertainties in the pre-exponential factors decreased significantly. When reactant concentrations are similar, as for $\mathrm{CO}$ oxidation by equimolar $\mathrm{O}_{2}$, a global fit of reaction profiles provides more reliable information about the reaction orders, in contrast to the individual fit of a single reaction profile (described above).

\section{Conclusions}


Accurate information about the activation parameters and the reaction order with respect to the limiting reactant can be obtained from a single curve-fit of a variable-temperature reaction profile recorded in the absence of transport limitations. The small number of adjustable parameters (as few as two) in the fit make it likely that a unique solution will be found. The reaction order with respect to an excess reactant may be refined by simultaneous curve-fitting of multiple profiles recorded at different volumetric flow rates. When multiple reactants are present in similar concentrations, global curve-fitting makes it possible to refine their reaction orders. Obviously, additional experiments with different feed gas compositions are desirable to establish the generality of the rate law. Since kinetic equations are fully separable from heat and mass transport equations in most situations, rate parameters obtained from variable-temperature profiles with dilute reactant concentrations are also valid with more concentrated feeds.

In principle, the method could be used for rapid and rigorous assessment of the effects of metal loading, metal particle size, support interactions, promoters and poisons in the gas and solid phases, on catalyst performance. For catalysts that deactivate on a time-scale longer than the recording of a reaction profile, variable-temperature kinetic analysis could allow for fuller kinetic assessment than is currently possible with conventional steady-state methods. The variable-temperature method can detect changes in the limiting rate law as a function of reaction conditions, and in the future could be extended to include diffusion effects, more complex rate laws, reversible reactions, side-reactions, and variable activation energies.

\section{Acknowledgements}

This work was supported financially by the US Department of Energy, Office of Science, Division of Basic Energy Sciences, under the Catalysis Science Initiative (DE-FG-02- 
03ER15467). D. H. C. thanks the PIRE-ECCI program (NSF OISE-0968399) and Air Products for fellowship support. We are grateful to Dr. Ryan Davis and Dr. Ta Na for the catalyst synthesis and characterization.

\section{Appendix A. Supplementary material}

Supplementary material associated with this article can be found, in the online version, at sciencedirect.com. 


\section{References}

[1] X.D. Xiang, X.D. Sun, G. Briceno, Y.L. Lou, K.A. Wang, H.Y. Chang, W.G. Wallace-Freedman, S.W. Chen, P.G. Schultz, A combinatorial approach to materials discovery, Science 268 (1995) 1738-1740.

[2] A. Hagemeyer, B. Jandeleit, Y.M. Liu, D.M. Poojary, H.W. Turner, A.F. Volpe, W.H. Weinberg, Applications of combinatorial methods in catalysis, Appl. Catal. A: Gen. 221 (2001) 23-43.

[3] B. Jandeleit, D.J. Schaefer, T.S. Powers, H.W. Turner, W.H. Weinberg, Combinatorial materials science and catalysis, Angew. Chem. Int. Ed. 38 (1999) 2495-2532.

[4] S.M. Senkan, S. Ozturk, Discovery and optimization of heterogeneous catalysts by using combinatorial chemistry, Angew. Chem. Int. Ed. 38 (1999) 791-795.

[5] T. Bligaard, R.M. Bullock, C.T. Campbell, J.G. Chen, B.C. Gates, R.J. Gorte, C.W. Jones, W.D. Jones, J.R. Kitchin, S.L. Scott, Towards benchmarking in catalysis in science: best practices, opportunities, and challenges, ACS Catal. Just Accepted (2016) DOI: 10.1021/acscatal.1026b00183.

[6] M. Boudart, Turnover rates in heterogeneous catalysis, Chem. Rev. 95 (1995) 661-666.

[7] S. Kozuch, J.M.L. Martin, "Turning Over" Definitions in Catalytic Cycles, ACS Catal. 2 (2012) 2787-2794.

[8] G. Lente, Comment on "'Turning over' definitions in catalytic cycles", ACS Catal. 3 (2013) 381-382.

[9] K. Hauff, H. Dubbe, U. Tuttlies, G. Eigenberger, U. Nieken, Platinum oxide formation and reduction during NO oxidation on a diesel oxidation catalyst-Macrokinetic simulation, Appl. Catal. B-Environ. 129 (2013) 273-281.

[10] E.J. Peterson, A.T. Delariva, S. Lin, R.S. Johnson, H. Guo, J.T. Miller, J.H. Kwak, C.H.F. Peden, B. Kiefer, L.F. Allard, F.H. Ribeiro, A.K. Datye, Low-temperature carbon monoxide oxidation catalysed by regenerable atomically dispersed palladium on alumina, Nat. Commun. 5 (2014).

[11] J.R. Kittrell, W.G. Hunter, C.C. Watson, Nonlinear least squares analysis of catalytic rate models, AIChE J. 11 (1965) 1051-1057.

[12] D.J. Pritchard, D.W. Bacon, Statistical assessment of chemical kinetic models, Chem. Eng. Sci. 30 (1975) $567-$ 574.

[13] M. Schwaab, J.C. Pinto, Optimum reference temperature for reparameterization of the Arrhenius equation. Part 1: Problems involving one kinetic constant, Chem. Eng. Sci. 62 (2007) 2750-2764.

[14] E. Koch, Non-isothermal reaction analysis, Academic Press, New York, 1977.

[15] B.W. Wojciechowski, N.M. Rice, Experimental methods in kinetic studies, Elsevier, Boston, 2003. 
[16] K. Hauff, U. Tuttlies, G. Eigenberger, U. Nieken, Platinum oxide formation and reduction during NO oxidation on a diesel oxidation catalyst - Experimental results, Appl. Catal. B-Environ. 123 (2012) 107-116.

[17] A.K. Galway, Kinetic background to thermal analysis and calorimetry, in: M.E. Brown (Ed.) Handbook of Thermal Analysis and Calorimetry, Elsevier, Amsterdam, 1998, pp. 147-224.

[18] A. Tiwari, B. Raj, Reactions and Mechanisms in Thermal Analysis of Advanced Materials, Wiley, Hoboken, New Jersey, 2015.

[19] E.S. Freeman, B. Carroll, The application of thermoanalytical techniques to reaction kinetics - the thermogravimetric evaluation of the kinetics of the decomposition of calcium oxalate monohydrate, J. Phys. Chem. 62 (1958) 394-397.

[20] A.W. Coats, J.P. Redfern, Kinetic parameters from thermogravimetric data, Nature 201 (1964) 68-69.

[21] J.B. Miller, H.R. Siddiqui, S.M. Gates, J.N. Russell, J.T. Yates, J.C. Tully, M.J. Cardillo, Extraction of kineticparameters in temperature programmed desorption - a comparison of methods, J. Chem. Phys. 87 (1987) 67256732.

[22] R.A. Demmin, R.J. Gorte, Design parameters for temperature-programmed desorption from a packed-bed, J. Catal. 90 (1984) 32-39.

[23] G. Alibrandi, Alternative accelerated methods for studying drug stability: variable-parameter kinetics, in: S.C. Gad (Ed.) Pharmaceutical Manufacturing Handbook: Regulations and Quality, Wiley, Hoboken, New Jersey, 2008, pp. 701-724.

[24] S.P. Asprey, B.W. Wojciechowski, N.M. Rice, A. Dorcas, Applications of temperature scanning in kinetic investigations: The hydrolysis of acetic anhydride, Chem. Eng. Sci. 51 (1996) 4681-4692.

[25] L.F. Brown, B.A. Robinson, Using temperature-programmed reaction for kinetics analysis of liquid-phase reactions, Chem. Eng. Sci. 41 (1986) 963-970.

[26] S.A. Birdsell, B.A. Robinson, Kinetics of aryl halide hydrolysis using isothermal and temperature-programmed reaction analyses, Ind. Eng. Chem. Res. 28 (1989) 511-518.

[27] M. Maeder, K.J. Molloy, M.M. Schumacher, Analysis of non-isothermal kinetic measurements, Anal. Chim. Acta 337 (1997) 73-81.

[28] G. Alibrandi, Nonisothermal spectrophotometric kinetics applied to inorganic reactions, Inorg. Chim. Acta 221 (1994) 31-34. 
[29] R. Romeo, G. Alibrandi, Structure-reactivity correlations for the dissociative uncatalyzed isomerization of monoalkylbis(phosphine)platinum(II) solvento complexes, Inorg. Chem. 36 (1997) 4822-4830.

[30] F.N. Hosseini, S.M. Nabavizadeh, Application of variable-temperature kinetic experiments to oxidative addition reactions of dimethylplatinum(II) complexes with alkyl halides, Transit. Met. Chem. 38 (2013) 699703.

[31] S.L. Zhang, T.L. Brown, Application of the non-isothermal approach to the kinetics of organometallic reactions: The substitution of $\left(\eta^{5}\right.$-pentamethylcyclopentadienyl)dicarbonylrhodium(I), Inorg. Chim. Acta 240 (1995) 427-433.

[32] N. Matthess, D. Schweich, B. Martin, F. Castagna, From light-off curves to kinetic rate expressions for threeway catalysts, Top. Catal. 16 (2001) 119-124.

[33] R.E. Hayes, F.H. Bertrand, C. Audet, S.T. Kolaczkowski, Catalytic combustion kinetics: Using a direct search algorithm to evaluate kinetic parameters from light-off curves, Can. J. Chem. Eng. 81 (2003) 1192-1199.

[34] A. Pandya, J. Mmbaga, R.E. Hayes, W. Hauptmann, M. Votsmeier, Global kinetic model and parameter optimization for a diesel oxidation catalyst, Top. Catal. 52 (2009) 1929-1933.

[35] C. Depcik, S. Loya, A. Srinivasan, T. Wentworth, S. Stagg-Williams, Adaptive global carbon monoxide kinetic mechanism over platinum/alumina catalysts, Catalysts 3 (2013) 517-542.

[36] J.E. Etheridge, T.C. Watling, Is reactor light-off data sufficiently discriminating between kinetic parameters to be used for developing kinetic models of automotive exhaust aftertreatment catalysts? The effect of hysteresis induced by strong self inhibition, Chem. Eng. J. 264 (2015) 376-388.

[37] D. Bhatia, M.P. Harold, V. Balakotaiah, Kinetic and bifurcation analysis of the cooxidation of $\mathrm{CO}$ and $\mathrm{H}_{2}$ in catalytic monolith reactors, Chem. Eng. Sci. 64 (2009) 1544-1558.

[38] N. Rankovic, A. Nicolle, D. Berthout, P. Da Costa, Kinetic modeling study of the oxidation of carbon monoxide-hydrogen mixtures over $\mathrm{Pt} / \mathrm{Al}_{2} \mathrm{O}_{3}$ and $\mathrm{Rh} / \mathrm{Al}_{2} \mathrm{O}_{3}$ catalysts, J. Phys. Chem. C 115 (2011) 20225-20236.

[39] C. Dubien, D. Schweich, G. Mabilon, B. Martin, M. Prigent, Three-way catalytic converter modelling: fast- and slow-oxidizing hydrocarbons, inhibiting species, and steam-reforming reaction, Chem. Eng. Sci. 53 (1998) 471 481.

[40] S. Sa, J.M. Sousa, A. Mendes, Steam reforming of methanol over a $\mathrm{CuO} / \mathrm{ZnO} / \mathrm{Al}_{2} \mathrm{O}_{3}$ catalyst, part I: Kinetic modelling, Chem. Eng. Sci. 66 (2011) 4913-4921. 
[41] F. Duprat, Light-off curve of catalytic reaction and kinetics, Chem. Eng. Sci. 57 (2002) 901-911.

[42] P. Stefanov, S. Todorova, A. Naydenov, B. Tzaneva, H. Kolev, G. Atanasova, D. Stoyanova, Y. Karakirova, K. Aleksieva, On the development of active and stable Pd-Co/gamma- $\mathrm{Al}_{2} \mathrm{O}_{3}$ catalyst for complete oxidation of methane, Chem. Eng. J. 266 (2015) 329-338.

[43] B.W. Wojciechowski, S.P. Asprey, Kinetic studies using temperature-scanning: the oxidation of carbon monoxide, Appl. Catal. A: Gen. 190 (2000) 1-24.

[44] S.P. Asprey, B. W. Wojciechowski, B.A. Peppley, Kinetic studies using temperature-scanning: the steamreforming of methanol, Appl. Catal. A: Gen. 179 (1999) 51-70.

[45] F.V. Hanson, M. Boudart, Reaction between $\mathrm{H}_{2}$ and $\mathrm{O}_{2}$ over supported platinum catalysts, J. Catal. 53 (1978) $56-67$.

[46] C.F. Cullis, T.G. Nevell, Kinetics of catalytic-oxidation over palladium of some alkanes and cycloalkanes, Proc. Roy. Soc. Lond. A 349 (1976) 523-534.

[47] T. Engel, G. Ertl, Molecular beam investigation of catalytic oxidation of CO on Pd (111), J. Chem. Phys. 69 (1978) $1267-1281$.

[48] D.E. Mears, Tests for transport limitations in experimental catalytic reactors, Ind. Eng. Chem. Proc. Des. Dev. 10 (1971) 541-547.

[49] P.B. Weisz, C.D. Prater, Interpretation of measurements in experimental catalysis, Adv. Catal. 6 (1954) 143 196.

[50] D.E. Mears, Diagnostic criteria for heat transport limitations in fixed bed reactors, J. Catal. 20 (1971) 127-131.

[51] A.M. Ganzler, M. Casapu, A. Boubnov, O. Muller, S. Conrad, H. Lichtenberg, R. Frahm, J.D. Grunwaldt, Operando spatially and time-resolved X-ray absorption spectroscopy and infrared thermography during oscillatory CO oxidation, J. Catal. 328 (2015) 216-224.

[52] A. Steigel, J. Sauer, G. Binsch, D.A. Kleier, Nitrogen analogs of cycloheptatrienes and norcaradienes. Nuclear magnetic resonance study of their thermodynamic and kinetic properties, J. Am. Chem. Soc. 94 (1972) 27702779.

[53] T. Uda, M. Tanaka, K. Munakata, Scaling up experiments of honeycomb catalysts for oxidation of hydrogen and methane gases, Fusion Eng. Des. 87 (2012) 900-904. 
[54] S.P. Asprey, Y. Naka, Mathematical problems in fitting kinetic models - Some new perspectives, J Chem. Eng. Jpn. 32 (1999) 328-337.

[55] G.E.P. Box, Fitting empirical data, Ann. N.Y. Acad. Sci. 86 (1960) 792-816.

[56] M. Aryafar, F. Zaera, Kinetic study of the catalytic oxidation of alkanes over nickel, palladium, and platinum foils, Catal. Lett. 48 (1997) 173-183.

[57] Y.F.Y. Yao, Oxidation of alkanes over noble metal catalysts, Ind. Eng. Chem. Prod. Res. Dev. 19 (1980) 293 298.

[58] A.D. Allian, K. Takanabe, K.L. Fujdala, X. Hao, T.J. Truex, J. Cai, C. Buda, M. Neurock, E. Iglesia, Chemisorption of $\mathrm{CO}$ and mechanism of $\mathrm{CO}$ oxidation on supported platinum nanoclusters, J. Am. Chem. Soc. 133 (2011) 4498-4517.

[59] J. Saavedra, H.A. Doan, C.J. Pursell, L.C. Grabow, B.D. Chandler, The critical role of water at the gold-titania interface in catalytic CO oxidation, Science 345 (2014) 1599-1602.

[60] L.L. Hegedus, S.H. Oh, K. Baron, Multiple steady states in an isothermal, integral reactor - The catalytic oxidation of carbon monoxide over platinum-alumina, AIChE J. 23 (1977) 632-642.

[61] P.J. Berlowitz, C.H.F. Peden, D.W. Goodman, Kinetics of CO oxidation on single-crystal Pd, Pt, and Ir, J. Phys. Chem. 92 (1988) 5213-5221.

[62] N.W. Cant, P.C. Hicks, B.S. Lennon, Steady-state oxidation of carbon monoxide over supported noble metals with particular reference to platinum, J. Catal. 54 (1978) 372-383.

[63] S.M. Landry, R.A.D. Betta, J.P. Lu, M. Boudart, Catalytic oxidation of carbon monoxide on palladium. 1. Effect of pressure, J. Phys. Chem. 94 (1990) 1203-1206.

[64] Y.F.Y. Yao, The oxidation of CO and hydrocarbons over noble-metal catalysts, J. Catal. 87 (1984) 152-162.

[65] S.M. McClure, D.W. Goodman, New insights into catalytic CO oxidation on Pt-group metals at elevated pressures, Chem. Phys. Lett. 469 (2009) 1-13.

[66] H. Conrad, G. Ertl, J. Koch, E.E. Latta, Adsorption of CO on Pd Single-Crystal Surfaces, Surf. Sci. 43 (1974) 462-480.

[67] W.K. Kuhn, J. Szanyi, D.W. Goodman, CO adsorption on Pd(111) - the effects of temperature and pressure, Surf. Sci. 274 (1992) 611-618. 
[68] J.H. Fischer-Wolfarth, J.A. Farmer, J.M. Flores-Camacho, A. Genest, I.V. Yudanov, N. Rosch, C.T. Campbell, S. Schauermann, H.J. Freund, Particle-size dependent heats of adsorption of CO on supported Pd nanoparticles as measured with a single-crystal microcalorimeter, Phys. Rev. B 81 (2010) 241416.

[69] J.M. Flores-Camacho, J.H. Fischer-Wolfarth, M. Peter, C.T. Campbell, S. Schauermann, H.J. Freund, Adsorption energetics of $\mathrm{CO}$ on supported Pd nanoparticles as a function of particle size by single crystal microcalorimetry, Phys. Chem. Chem. Phys. 13 (2011) 16800-16810.

[70] M. Peter, S. Adamovsky, J.M.F. Camacho, S. Schauermann, Energetics of elementary reaction steps relevant for $\mathrm{CO}$ oxidation: $\mathrm{CO}$ and $\mathrm{O}_{2}$ adsorption on model Pd nanoparticles and Pd(111), Faraday Discuss. 162 (2013) 341-354.

[71] O. Dulaurent, K. Chandes, C. Bouly, D. Bianchi, Heat of adsorption of carbon monoxide on various Pdcontaining solids using in situ infrared spectroscopy at high temperatures, J. Catal. 192 (2000) 273-285.

[72] A.K. Santra, D.W. Goodman, Catalytic oxidation of CO by platinum group metals: from ultrahigh vacuum to elevated pressures, Electrochim. Acta 47 (2002) 3595-3609.

[73] B.M. Kunkel, B.C. Peoples, C.M. Yung, S.L. Scott, Clay-catalyzed cracking leads to suppressed flammability in clay-polyolefin nanocomposites, Macromol. Mater. Eng. 296 (2011) 1075-1080. 
Table of Contents graphic

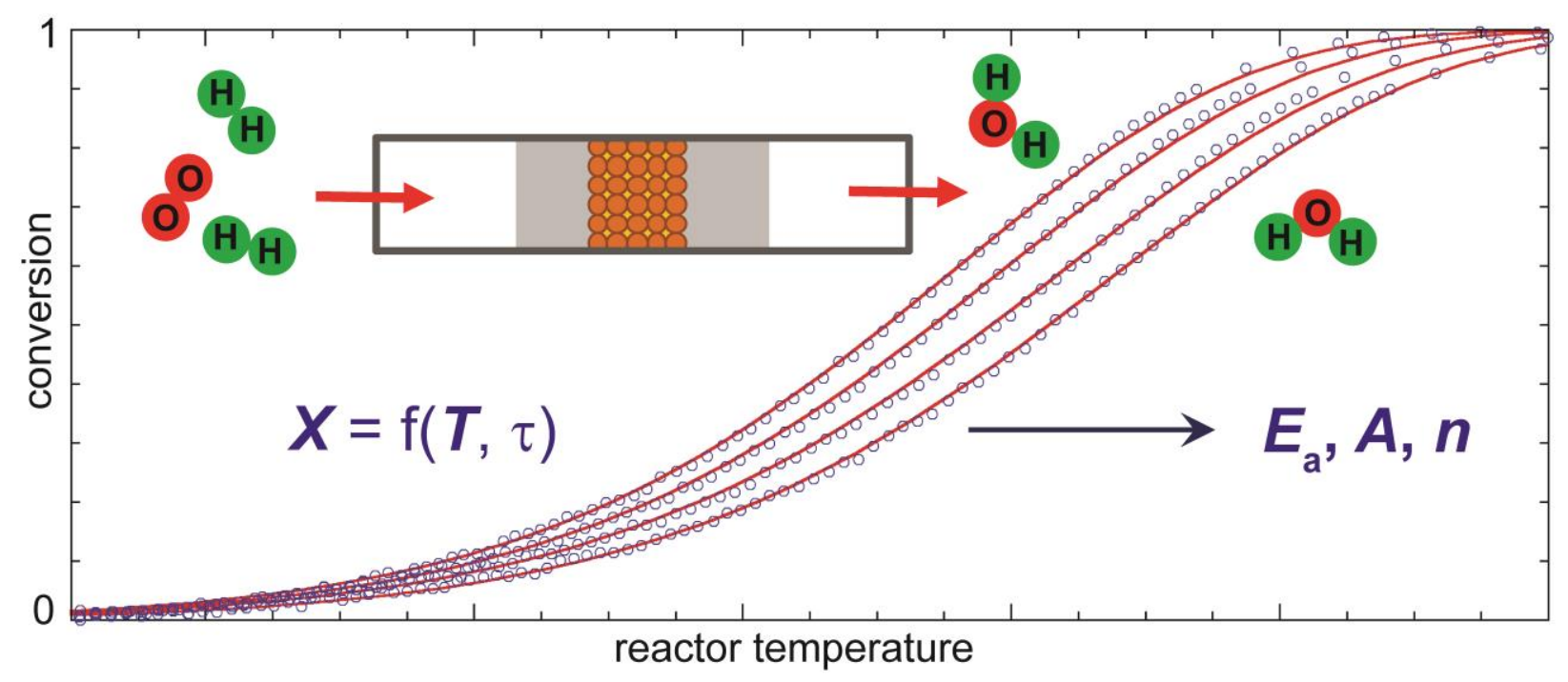

